\title{
GUERRA, PAZ, ...DEMOCRACIA? El Salvador de 1979 a 1994: una interpretación dialéctica
}

\author{
Ricardo Ribera*
}

\section{Breve reflexión epistemológica}

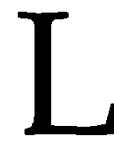

a complejidad con que en El Salvador se ha desarrollado el proceso histórico a partir de 1979 es algo probablemente aceptado por cualquier observador medianamente informado. Su interpretación requiere cierta profundidad en el análisis, por lo que en algunos fragmentos nuestra exposición adquirirá alguna densidad teórica, que esperamos no desaliente a nuestro

"Los individuos y los pueblos, al buscar satisfacer sus propios fines son a la vez el medio $e$ instrumento de algo superior, que realizan inconscientemente... surge algo més que lo que los hombres se proponen, mís de lo que ellos saben y quieren inmediatamente." (G.W.F. Hegel)

"La reoolución francesa cumplió con ropaje y lenguaje romanos la misión de su tiempo... (los hombres) encontraron en las tradiciones romanas los ideales $y$ les ilusiones que necesitaban para ocultarse a si mismos el contenido burguesamente limitado de sus luchas." (K. Marx) 1

- Historiador y Catedrático del Departamento de Filosofía de la UCA.

1. G.W.F. Hegel: "Lecciones sobre la filosofia de la historia", Alianza Ed., Madrid, 1980, pág. 85; K. Marx: "El 18 Brumario de Luis Bonaparte", Ed. Grijalbo, Col. 70, \#139, México, 1974, págs. 18 y 19. 
potencial lector. Perseguimos con ello alcanzar una comprensión más completa sobre el sentido y significación de las múltiples facetas que presentan estos quince años de historia salvadoreña. Por tanto, lo invitamos cordialmente a acompañarnos en las siguientes páginas y a que reflexionemos juntos al respecto.

Posiblemente su lectura, cuando quien nos lee ha participado, directa o indirectamente, en los sucesos de la historia salvadoreña reciente, puede hacer despertar recuerdos y vivencias. Si los que, de alguna forma, han sido protagonistas reaccionan a nuestro texto exclamando "así fue!", consideraremos que eso viene a validar nuestra labor, volviéndola socialmente útil. Es decir, la validez de la investigación - una vez asegurado que son correctos los datos y hechos sobre los que construimos nuestro discurso histórico- vendría dada a partir de que los sujetos reconozcan como auténtica la interpretación que ofrece el historiador. Preferimos considerar el criterio de autenticidad como categoría valorativa y no el criterio de verdad, conscientes de lo relativo de cualquier pretensión de veracidad cuando se trata, como en este caso, de una historia del tiempo presente, referida además primordialmente a la esfera ideológica.

Con frecuencia el historiador se sitúa frente al pasado sin más ambición que la que le dicta el oficio: tratar de reconstruir, lo más fidedignamente posible, los acontecimientos que le parezcan relevantes y los motivos que los presidieron, interrogarse por las causas de los mismos y reflexionar sobre sus consecuencias. El pasado -según esta visión tradicional- es tratado básicamente como simple pasado, sin que aparezca su encadenamiento con el presente ni sean explícitos los problemas y preocupaciones de la actualidad que condicionan al historiador, quien pretende validez imperecedera para su "aséptica" labor. Desvinculada del "aquí y ahora" el precio que paga la historiografía tradicional es su escaso interés, que se reduce a la curiosidad intelectual de algunos o al elitista afán de erudición de otros.

En contraste, proponemos un enfoque que toma como punto de partida una apreciación mucho más modesta sobre los resultados de la investigación histórica, a los que asignamos validez únicamente temporal. En contrapartida somos mucho más ambiciosos en nuestra aspiración de lograr cierta eficacia del discurso históri- 
co. "Hacer historia" debe tener, según nosotros, el doble sentido que sugiere dicha expresión textual, tanto en el de escribir sobre ella como en el de incidir sobre el acontecer actual. Ello no significa desvalorizar la paciente labor historiográfica de reconstrucción del pasado, la elaboración cuidadosa del tapiz de la historia escrita, finamente bordado de ideas, acontecimientos y circunstancias del pasado, el casi detectivesco ejercicio de descubrir y seguirle "el hilo" al proceso. Pero - si se nos permite la imagen - lo hacemos convencidos de que siguiendo el hilo llegaremos a la madeja... la cual no consideramos tirada en algún rincón del pasado sino que se halla en nuestras manos, está siempre ubicada en la actualidad.

En consecuencia, trataremos de imprimirle un enfoque "hacia adelante" al trabajo historiográfico, habitualmente concebido como un sencillo remontarse "hacia atrás". De tal forma, el tiempo histórico que es objeto de estudio no debe hacernos olvidar aquél otro en el que se encuentra inmerso el sujeto que estudia. Ambos, sujeto y objeto, se hallan interrelacionados, condicionándose en buena medida el discurso histórico en esta relación. Por tanto, en el trabajo historiográfico ni la total subjetividad será válida, ni la completa objetividad será posible. Cualquier pretensión de objetividad absoluta debería ser considerada sospechosa, o bien de intención manipuladora, o bien de ingenuidad inconscientemente ideologizada.

La objetividad resulta para el historiador en un criterio necesario pero relativo, por lo inalcanzable. A la vez, le será francamente imposible la neutralidad o la imparcialidad, pues como ser humano se encuentra comprometido con la realidad histórica y social. Tiene en ella intereses, valores e ideales que defender; desarrolla involuntaria y espontáneamente simpatías, antagonismos, identificaciones y rechazos con el diverso material objeto de su estudio. Por todo ello su discurso histórico será necesariamente parcial, interesado y, sólo de manera relativa, podrá ser objetivo. De ahí se desprende que nunca quede dicha "la última palabra" en el análisis histórico. Con mayor razón cuando se trata de historia del tiempo presente, de acontecimientos en los que el propio historiador ha sido testigo o partícipe, cuando los hombres que los protagonizaron están muchos de ellos vivos y pueden ser interpelados. Mas, lo afirmado antes también es válido en otro tipo de estudios históricos pues, como señalaba $\mathrm{Hegel}$, cada época se ve precisada a 
reescribir la historia. Esta ofrece tan variadas facetas que no agota sus posibilidades ni en el más voluminoso y erudito estudio historiográfico.

Al igual que el presente viene condicionado por el pasado, aquél condiciona a su vez la visión que obtiene del segundo; las preguntas que ahora le formulamos al pasado no son las mismas que hacíamos una década antes ni las que podamos plantear, por ejemplo, dentro de un lustro. Ello refleja una triple dimensión del tiempo histórico, que en cada momento del proceso aparece simultáneamente como pasado, presente y futuro. El tiempo histórico escenificado como pasado representa la acumulación de lo ya actuado en tanto potencialidad realizada. Como presente expresa la tensión entre el condicionamiento legado por el pasado y la voluntad proyectada hacia el futuro. En cuanto futuro se muestra como un horizonte donde puede vislumbrarse un devenir en estado de potencialidad objetiva y la configuración subjetiva de la acción y voluntad de los hombres. La naturaleza triádica del tiempo histórico permitirá al historiador descubrir dialécticamente tres dimensiones en el despliegue del proceso histórico que analiza, los que requerirán tres niveles interpretativos sucesivos.

En nuestro caso, al analizar dialécticamente el proceso salvadoreño de 1979 a 1994, tratando de hacer su historia estructuramos en realidad tres historias complementarias. Al buscar una comprensión crítica del pasado inmediato, construimos una historia de la guerra; en segundo término, nos aparece una historia de la paz al intentar descifrar los interrogantes del presente; por último, se nos dibuja una historia de la democracia, como un mero esbozo de posibilidades del futuro mediato, aún incierto $\mathrm{y}$ pendiente de verse frustrado o confirmado.

\section{Consideraciones para una historia de la guerra}

$\mathrm{H}^{1}$ período nos aparece como un tiempo de guerra: es el nivel $\triangle$ más evidente para el observador, pues el conflicto bélico aparentemente lo absorbía todo, lo dominó y lo sobredeterminó todo a lo largo de la década precedente, extendiendo su signo hasta fines de 1992. Desde este primer punto de vista, el estudio histórico se mantiene dentro de los límites de lo que un análisis fehacien- 
te del pasado ya realizado, del tiempo ya cumplido, puede aportar para su comprensión objetiva. Desde ella se intentará posibilitar "un mejor situarse" en el presente histórico, frente a las actuales urgencias sociales y políticas, precisadas de acción y de conciencia histórica responsable sobre la necesidad de tal acción. Podríamos decir resumidamente que el rechazo y superación de la guerra, mediante la voluntad política nueva y la renovada praxis, para lograr efectividad y profundidad, requieren de "un conocer suficiente" sobre la realidad histórica de lo que ha sido el fenómeno "guerra civil" en El Salvador de los tiempos recientes.

Lo anterior significa que nuestra historia de la guerra no se reduce, ni es ése su interés principal, a una historia militar de la guerra, por más que ésta sea una dimensión que debemos tomar en cuenta. Desde nuestro presente no nos interesa tanto descubrir la lógica de la guerra, como la lógica de la paz. Dicho de otra forma, no nos sirve de mucho un enfoque estático como el que propone la lógica formal. Esta postula, por ejemplo, el principio conocido como de identidad, $\mathrm{A}=\mathrm{A}$ : la guerra es la guerra o, en su formulación negativa, la guerra no es la paz. La lógica dialéctica, que es la del movimiento, nos resulta mucho más sugerente; $\mathrm{A}=$ no-A, lo que en nuestro caso se puede traducir: de la guerra surgió la paz, la guerra se negó a sí misma, de la guerra se generó la no-guerra.

Es decir, por largo tiempo la dinámica del conflicto empujaba a más guerra - tal como su prolongación y la escalada bélica lo evidencian- pero, a partir de cierto momento, la guerra empezó a generar la negación de sí misma. ¿Cómo se dio este cambio? Sólo desde la dialéctica es posible enfocar dicho problema. Es claramente un movimiento de índole dialéctica el que mediante un salto cualitativo hace surgir en El Salvador la paz actual, constituida en negación de la negación. O sea, es negación de la guerra, la cual había negado a su vez la falsa paz anterior, y es también negación de esa paz de los años setenta, que incubaba la violencia explosiva de los ochenta. La paz de ahora -distinta, cualificada y superior a la paz del período previo a la guerra- no viene misteriosamente del aire sino que es justamente fruto del desarrollo del conflicto armado, que generó su propia contradicción hasta llegar a negarse a sí mismo. Será por tanto desde esta lógica, y no desde 
una unilateral lógica militar, que nos interesa construir la historia de la guerra en El Salvador de 1979 a 1994. Ello no obsta que podamos y debamos decir algunas cosas sobre la evolución propia de la dinámica militar durante este período.

\section{Evolución de la dinámica militar}

E s de señalar, al respecto, cómo en los primeros años del condad salvadoreña, generadas a lo largo de la década de los setenta, condujo a que se desarrollara el componente militar y que adoptara características de factor dominante y absoluto. Esta absolutización se expresó en la búsqueda por ambos bandos de la simple y llana aniquilación del contrario. Una franca estrategia estatal de genocidio, era respondida con preparativos para una insurrección generalizada de masas del lado insurgente. En el marco de exasperación social de las contradicciones, sólo la racionalidad perversa del aniquilamiento y el horror de la destrucción parecían presidir esos tiempos de pesadilla. El terror estatal era contestado con violencia asimismo extrema. Las víctimas se multiplicaban por doquier, sin que se hicieran distingos por razones de edad, de sexo, ocupación o nacionalidad. Tampoco se diferenciaba mayormente entre adversarios activos o pasivos, militantes o simples simpatizantes, combatientes o cuadros políticos e intelectuales. El mismo afán destructor parecia arrastrar a todos, tanto actores políticos como sujetos sociales, a una violencia realmente ciega, dominada por la pura razón negativa, donde la guerra quedaba identificada plenamente con la muerte, con la negación absoluta, entronizando ideológicamente en los tiempos el signo de lo irracional.

Al frustrarse la meta inicial de destrucción del contrario y de victoria total, la misma prolongación de la guerra llevó a que ésta tuviese que reconocer la lógica de las llamadas "leyes de la guerra" - según lo que algunos teóricos llaman "ciencia militar" - y acatar su dictado. La simple búsqueda de la destrucción inmediata y total más reflejaba en las partes una conducta cargada de pasión, odio y venganza, que una conducción coherente y racional de las actividades bélicas. Debía aceptarse una mayor racionalidad y superarse el nivel de lo elementalmente emotivo, introduciéndose en el proceso la contradicción de que la razón pasara a encabezar el 
esfuerzo irracional de la guerra. Esta siguió teniendo características absolutas -de guerra total-durante los siguientes años, pero sujeta ahora a cierto ordenamiento que la subordinaba a un diseño estratégico racionalmente planificado.

El caos y espontaneidad prevalecientes en el tiempo inmediatamente anterior iba quedando superado, tendiéndose más bien hacia un esquema de guerra regular. La Fuerza Armada tomaba el control del esfuerzo bélico gubernamental, subordinando la acción de cuerpos de seguridad, organismos de inteligencia y estructuras paramilitares a un diseño centralizado bajo comando del Estado Mayor. También la guerrilla tendía ahora a un accionar con esquemas más cercanos a la guerra regular, concentrando su fuerza y estructurándola convencionalmente en escuadras, pelotones, columnas, e incluso batallones y brigadas. La dinámica obligaba al FMLN a complejizar sus redes de logística y abastecimientos, de inteligencia, de propaganda, etc.; desarrollaba estructuras auxiliares como sanidad militar, talleres, cocina, etc.; creaba unidades de armas de apoyo (artillería), de operaciones especiales (comandos), etc.

El FMLN adoptaba ahora una redefinición estratégica por la que desechaba simplificadas concepciones insurreccionalistas, así como otras esquemáticamente copiadas de otros países. La insurgencia salvadoreña dejaba de ver la campaña sandinista contra el somocismo - que dirigió la tendencia tercerista del FSLN- como un modelo a imitar, mientras planteamientos influidos por el maoísmo, por el foquismo, por la línea pro-soviética o por la trotskista, no van a poder prevalecer en un proceso que revela rasgos originales y novedosos, ante los que hay que inventar lo nuevo, pues no sirve la copia de lo ya conocido. La fórmula "guerra popular revolucionaria" le daría nombre a dicha renovación del pensamiento estratégico del FMLN, el cual concibe su propia experiencia como más cercana a la vietnamita que a la de la vecina $\mathrm{Ni}$ caragua. En la medida que fue acrecentándose la intervención norteamericana en El Salvador, los paralelismos de este proceso con el vietnamita cobraban visos más consistentes.

Desde 1984, cuando Estados Unidos consiguió imponerle a la Fuerza Armada salvadoreña su estrategia "de baja intensidad" y apoyó la apertura del diálogo por Duarte, el FMLN comprendió la 
necesidad de enfocar la guerra de forma más integral y de estudiar en detalle la experiencia de los camaradas vietnamitas. Uno de los cambios fundamentales sería darle la preeminencia a lo político por sobre lo estrictamente militar. En la nueva concepción, el partido debía dirigir a su ejército "en forma directa, total y absoluta", para garantizar el rumbo revolucionario de la guerra y superar las tendencias militaristas. Diferentes responsables político-militares fueron nombrados por los partidos integrados en el FMLN, a fin de asumir la conducción integral en los frentes. Por otro lado, los revolucionarios vietnamitas habían sostenido en Ginebra y Paris conversaciones de paz con sus enemigos "imperialistas" a lo largo de 8 años, mientras simultáneamente seguían desarrollando su guerra de liberación. La posibilidad de una combinación semejante de lo militar, lo político y lo diplomático, resultaba muy atractiva para la insurgencia salvadoreña. Esta ensayó una línea estratégica de "guerra con negociación", buscando una evolución parecida para su propio proceso. Aunque éste tomó finalmente por otro rumbo, cabe señalar que, curiosamente, también en El Salvador se extendería por aproximadamente 8 años el proceso de diálogo-negociación, desde la primera ronda de La Palma en octubre de 1984, hasta el Acuerdo de Paz de Chapultepec en enero de 1992.

En el bando gubernamental, se daba la asimilación por el ejército de la concepción integral contenida en la estrategia estadounidense "de baja intensidad" y la conformación de unidades más livianas para la puesta en práctica de tácticas irregulares de combate, una vez vencida la anterior resistencia del Alto Mando salvadoreño. Al mismo tiempo, empezaba a tener resultados exitosos la combinación del patrullaje constante de los livianos batallones "de cazadores" con operativos de gran envergadura y la acción de las PRAL (Patrullas de Reconocimiento de Alcance Largo), que se infiltraban hasta la profundidad de las zonas controladas por la guerrilla, ubicando puestos de mando e infraestructuras vitales y guiando desde el terreno los bombardeos aéreos y el desembarco de paracaidistas. Entre 1984 y 1985 la institución castrense lograba retomar la iniciativa militar y aspiraba a capitalizar en un futuro próximo sus esfuerzos por aislar política y socialmente al FMLN de la franja central del territorio, donde reside y labora el grueso de la población. El Frente tuvo que reconocer, internamente, que 
la gubernamental acción cívico-militar hacia el campesinado tenía mayores alcances que una simple campaña de propaganda. El gobierno se basaba en la idea de "ganar la mente y los corazones" de la población, según la concepción de que esta guerra era "en un $90 \%$ de carácter político y sólo en un $10 \%$ de naturaleza militar". Todo ello demostraba la vulnerabilidad de las fuerzas guerrilleras fuertemente concentradas y lo negativo de su tendencia a una menor movilidad. El FMLN se vio forzado a reaccionar, regresando a la desconcentración e irregularidad típicas de la guerra de guerrillas, superando su anterior tendencia a regularizar su ejército revolucionario.

El efecto directo de esta nueva conceptualización de la guerra por los dos contendientes fue su alargamiento, prácticamente indefinido. Ambas partes se centraban ahora en una estrategia semejante de desgaste de su enemigo, con lo que el conflicto se extendía territorialmente afectando a más población civil y escalaba paulatinamente en intensidad, involucrando armamento cada vez más sofisticado. No obstante, parecía consolidarse una situación relativamente empatada, llamada técnicamente por los estrategas como de "equilibrio militar estratégico". En un conflicto básicamente irregular, en una guerra civil de estas características, los expertos dicen que "quien no va ganando es porque va perdiendo"; paradójicamente, en El Salvador ninguno de los bandos parecía ir ganando. La guerra se hacía cada vez más indefinida y amenazaba con un proceso de "libanización" del país. El conflicto incluía una intensa actividad diplomática, saturación propagandística, así como maniobras políticas internas con los partidos legales y en el marco de la institucionalidad. Se hacían operaciones propias de la guerra psicológica, prácticas de reclutamiento forzoso, acciones terroristas ocasionales prácticamente de carácter indiscriminado, sabotaje sistemático a la producción e infraestructura económica. Además se utilizaban medios bélicos que provocaban gran cantidad de víctimas civiles, como los bombardeos aéreos efectuados a gran altura, el uso de artillería de largo alcance y la siembra indiscriminada de minas antipersonal y artefactos "caza-bobos".

Llegados a 1989 - tras una década de conflicto y más de cinco años de guerra integral - era evidente el estado de agotamiento en que se hallaba el país y el "cansancio de la guerra" entre la 
población. La situación bélica aparecía básicamente empantanada y nada se veía capaz de alterar ese equilibrio dinámico, mientras ambas partes mostraban signos de desgaste, no tanto material como psicológico y moral. Se hacian cada vez más numerosos los casos de deserciones, abusos de autoridad, irrespeto a la población, corrupción y enriquecimiento personal, en el "río revuelto" de la confrontación militar, que movilizaba grandes recursos logísticos y financieros. Urgía una definición del proceso, para la que la parte gubernamental no parecía preparada, mientras el FMLN ensayó una doble vía: la contraofensiva militar estratégica concretada en su campaña "hasta el tope", más conocida como "la ofensiva" en noviembre del 89-, y la negociación directa que pudiera abrir paso a una solución política, sobre la base de concesiones mutuas entre los contendientes. Fracasada en sus objetivos máximos la ofensiva de noviembre, la misma insuficiencia en la correlación de fuerzas le demostraría pronto al Frente la inviabilidad de una estrategia de "guerra con negociación" inspirada en la experiencia vietnamita. En este marco, la dinámica que emanaba de la mesa de negociación empezaba a imponerse y, aunque lo militar se mantenía como fuerte factor de presión, había perdido el papel determinante. La dinámica militar había pasado, de ser el factor dominante en el proceso, a una posición meramente determinante del mismo sin su dominancia anterior, hasta quedar finalmente desplazado por la nueva determinación centrada ahora en la dinámica negociadora.

De esa forma se llegó al desenlace negociado, propagandizado por ambas partes como una solución "sin vencedores ni vencidos". Políticamente los compromisos alcanzados parecerían favorecer ampliamente al FMLN, que obtuvo muchos de los objetivos que se había propuesto en su programa de revolución democrática de 1990, aunque distaba bastante de los radicales propósitos programáticos de su plataforma inicial de gobierno democrático-revolucionario. Pero, desde el punto de vista estrictamente militar el dictamen del gran teórico Clausewitz sugiere todo lo contrario -"el objetivo último de toda guerra es desarmar al adversario"- , dada la entrega de armas y el desmontaje de la estructura militar del FMLN, cuando la Fuerza Armada sólo resulta depurada y reducida. Por otra parte, en el nivel ideológico, los sectores 
empresariales dominantes y la ideología hegemónica del capitalismo neoliberal son los que resultaron reforzados. El balance final, por tanto, debe matizarse mucho y no puede ser sino paradójico: nadie ganó en la guerra mas, sin embargo, bastantes perderian con la paz. La presencia de muchos intereses particulares que quedarían afectados con la paz - y que se venían imponiendo a despecho del prioritario interés social, nacional o patriótico que unos y otros decían encarnar- puede explicar, en parte, el que se haya dado esa absurda e insensata prolongación de un conflicto que, para ambos bandos, desde hacía mucho carecía de perspectivas de victoria.

\section{Dialéctica entre actores políticos y sujetos sociales}

T a breve crónica militar que acabamos de esbozar sirve para Ldejar reflejada la evolución que tuvo una relación dialéctica de importancia relevante: la establecida entre los sujetos sociales y los actores políticos. Debe destacarse el contraste entre la fase inicial del conflicto y la última; mientras a fines de los setenta y principios de la década pasada era notable la situación social de efervescencia de masas y las grandes movilizaciones populares, esa participación activa en el proceso se va perdiendo a medida que el conflicto se desarrolla, se extiende y va alargándose. Se volvió generalizada una conducta ciudadana de expectación pasiva, en la que se mantenían vivas las simpatías y opción particular de cada uno, pero desde afuera del accionar cotidiano. De esta actitud expectante, una gran mayoría se va deslizando poco a poco a la posición del simple espectador, que ya no vibra con las noticias del proceso, sino que se limita a contemplarlo en los informativos y se vuelve cada vez más neutral, en la medida que lo vive como algo ajeno. El escalón siguiente en esa tendencia fue la desmovilización, la cual incubaba una nueva convicción de masas: la de que la guerra no iba a solucionar nada y que debía terminar cuanto antes. El último paso en esa evolución sería la indiferencia, perceptible en segmentos relativamente amplios de la población, que vendría a expresar el opuesto dialéctico a la polarización y fervor político de principios de la guerra. Terminada ésta, no sólo ha dejado de interesar la política y los políticos, sino que tampoco es apreciada mayor diferencia entre unos y otros; la indiferencia refleja el 
desinterés, pero también el hecho de que a los actores políticos se los percibe básicamente indiferenciados.

Recordemos que el conflicto se había iniciado como una auténtica "guerra civil", es decir, no sólo de carácter interno, sino también con una gran cantidad de civiles participando activamente en ella. Con la creciente profesionalización militar de las fuerzas enfrentadas se fue perdiendo esa connotación civil inicial, diferenciándose cada vez más el pueblo de su "brazo armado", la masa de la vanguardia, los combatientes de los civiles. Estos pronto dejaron de sentir como "suya" una guerra que se desarrollaba sin ellos y, en gran medida, a costa de ellos. Mientras la voluntad mayoritaria se iba inclinando por una finalización rápida de la guerra, sus protagonistas, por el contario, se comprometían en nuevas estrategias para asegurar su prolongación. Así, las partes beligerantes iban divorciándose poco a poco de los que antes habian sido base social, simpatizantes o colaboradores de su proyecto histórico. La extendida práctica por ambos bandos del sabotaje económico y la destrucción de cosechas, del reclutamiento forzoso que literalmente arrancaba a los hijos de sus familias y de modalidades coercitivas para la obtención de diversas ayudas de la población civil, -en víveres, dinero o información-, refleja el fracaso de las dos partes, que no supieron mantener vivas sus raíces originarias y el respaldo social espontáneo a su proyecto.

Una vez instalada la negociación se hizo pronto evidente la escasa credibilidad de que se habían hecho merecedoras las dos partes a los ojos del grueso de la población salvadoreña. Incapaces de volver a galvanizar el entusiasmo popular en torno a ellos, los actores políticos experimentaban un síndrome parecido a la llamada "soledad del corredor de fondo". Pocos habían estado dispuestos a acompañarlos en una tan larga carrera como son doce años de guerra, ni se movilizaban ahora ante un asimismo prolongado y complejo proceso de negociación, que además se desarrollaba con escasa información pública a partir del mutuo compromiso de confidencialidad. En tales condiciones de repliegue de masas la negociación se entablaba entre dos partes que, en el fondo, eran perdedoras ambas. Se habían mostrado incapaces una y otra de poder ganar la guerra, responsables las dos de haberla alargado inútil e innecesariamente, en contra de los deseos de su pueblo. 
Puede, por tanto, concluirse que los sujetos sociales son los que en buena medida determinaron, no tanto con las siempre débiles movilizaciones pacifistas como con su pasividad, el que los actores políticos se vieran compelidos a firmar la paz. Esta aparece como una victoria del pueblo salvadoreño, tal como se proclamó oficialmente en los medios de comunicación y en los discursos de los dirigentes. Sin embargo, éstos no hicieron mención a una cuestión que no debe quedar silenciada: ¿sobre quién obtuvo el pueblo su victoria? La respuesta: sobre ambas partes contendientes. Desde esta interpretación radical se entiende lo débil de la reconciliación, pues ésta se ha dado en forma mínima y únicamente entre las cúpulas de las contrapartes, pero falta entre éstas y el pueblo salvadoreño, principal víctima y testigo de excepción del desastre nacional de la guerra que asoló al país.

Según esta lectura que proponemos del proceso, los sujetos sociales fueron determinantes en el primer periodo de estallido de la guerra civil, arrastrando a los actores políticos, aún a los más vacilantes, al torbellino del conflicto interno. Volverian a serlo en la fase culminante del proceso, aunque el protagonismo aparente de los participantes en la mesa de negociación encubra el papel determinante que jugaba la posición política del sujeto histórico, firmemente definido contra la guerra y, consecuentemente, contra quienes pretendieran mantenerla, prolongarla o reanudarla. En conclusión, cabe decirse que a los actores políticos les faltó sensibilidad hacia los sujetos sociales. Frente a sus subordinados, bases o militantes demostraban fehaciente voluntad de victoria, pero no lograron convencer en su momento a la población de estar asimismo impregnados de una genuina voluntad de paz, que es lo que la historia y su pueblo les exigía. El proceso electoral de 1994, con su elevado ausentismo, escaso entusiasmo entre los votantes y resultados electorales marcados por la inercia y la apatía, puede interpretarse como una advertencia del pueblo -instrumentalizado tantas veces durante el conflicto- a los partidos políticos y sus dirigentes, recordándoles que sólo son y sólo deben ser instrumentos suyos, de sus intereses y voluntad, y nunca al revés. 


\section{Dialéctica entre dinámica militar y dinámica política}

T a relación dialéctica más general que preside el movimiento \lrcorner procesual que hemos definido como historia de la guerra es la que se establece entre las que denominamos "dinámicas" del proceso. Entendemos por "dinámica" el movimiento específico del conjunto de iniciativas, actuaciones y hechos generados por los actores politicos en una esfera concreta de la actividad, en vistas a su propia acumulación de fuerzas y a la confrontación con sus adversarios. Hemos identificado en el proceso salvadoreño que estudiamos las siguientes seis dinámicas: militar, política, social (o de masas), internacional (o diplomática), económica e ideológica. En cada uno de dichos escenarios activaban las partes beligerantes mediante una o varias políticas específicas. Así, por ejemplo, en la dinámica económica interactuaron simultáneamente una política castrense de destrucción sistemática de cultivos en las zonas conflictivas y una política gubernamental de reactivación de la economía nacional, frente a las políticas insurgentes de desarrollo productivo en sus zonas de control y de sabotaje al sistema productivo nacional. En el caso de la dinámica política quedaban incluídas en ella diversas políticas: de alianzas, de propaganda, de diálogo-negociación, de “democratización" y elecciones, etc.

Pues bien, la dinámica general del proceso histórico del período que estudiamos, su movimiento, aparecerá como resultante de la relación puntual entre unas y otras dinámicas, constituyéndose desde ella la secuencia de las coyunturas, la tendencia general del periodo y los saltos cualitativos que señalarán el paso de una fase a la siguiente. Desde este marco metodológico es posible calificar con mayor precisión cada coyuntura y apreciar mejor las tendencias. Con lo dicho hasta ahora podemos ya adelantar una propuesta de periodización, la cual quedará después más ampliamente justificada. Creemos que pueden observarse, a grandes rasgos, 5 períodos en el proceso bélico. El primero, al que podemos denominar periodo de la guerra total, abarca de 1979 a 1983. En él el factor militar aparace claramente dominante, expresando un fenómeno histórico que caracterizamos como la militarización de la politica. El segundo período, aproximadamente desde 1984 hasta 1988, al que llamamos de guerra integral, arranca con el despliegue del esquema norteamericano de guerra de baja intensidad y supone 
una inversión respecto el momento dialéctico anterior: encontramos que se produce ahora la politización de la guerra. Mientras en el primer periodo lo militar aparecía contrapuesto a lo político, pues la actividad política quedaba absorbida por el esfuerzo bélico, subsumida a éste, ahora en cambio la dinámica militar requiere de la dinámica política e igualmente a la inversa. Ambas se necesitan mutuamente y se condicionan, en una relación que no es armónica sino contradictoria, lo que aparece evidenciado con el despliegue del diálogo a partir de octubre de 1984.

Sigue un tercer periodo de corta duración, que juega el papel de un puente o de una transición, el cual ubicamos en el año 1989 y al que consideramos como de búsqueda de la definición. En él se exterioriza la relación complementaria y a la vez contradictoria entre las dinámicas militar y política, que se ha larvado en el período anterior. Por una parte ambas se identifican, por otra se diferencian. Los contendientes, urgidos por definir la guerra y precipitar un desenlace, perciben que la política de negociación podría significar una alternativa para obtener lo esencial de sus propósitos mediante una forma distinta a la victoria militar, pero a la vez se dan cuenta de que utilizando esa vía sus metas podrian verse sensiblemente alteradas o reducidas. Analíticamente este periodo expresa la configuración del momento dialéctico que Hegel describía como "identidad de la identidad y de la no-identidad"; o sea, para las partes la solución negociada podría ser equivalente a la salida militar y por tanto deseable, pero al mismo tiempo ven una diferencia en ambos desenlaces, implican distintos escenarios de postguerra, prefiguran diferentes correlaciones de fuerza, por lo que no pueden considerarlos equiparables. En consecuencia, las contrapartes se inclinarán en el período inmediatamente siguiente a probar una y otra modalidad para el desenlace de la guerra, las cuales han dejado de verlas contrapuestas, sino que son paradójicamente percibidas como idénticas y a la vez como diferentes.

En el cuarto periodo, de guerra con negociación, realidad que presidió el acontecer entre 1990 y 1991, aparecen bajo la forma de un dilema las opciones por la solución militar o por la política. En este período la dinámica militar tenderá a quedar desplazada por el componente negociación y por las transformaciones ideológicas consiguientes. A partir de septiembre de 1991, con el decisivo en- 
cuentro en Nueva York, se concretará esta tendencia al desplazamiento, no sin provocar una reacción postrera del militarismo, que trató de sobreponerse e intentó con sus provocaciones impedir a última hora el arranque del proceso de paz.

Este, iniciado el 16 de enero de 1992 y concluido oficialmente en marzo de 1994 con la celebración del evento electoral, desde el punto de vista de la historia de la guerra debemos llamarlo, más apropiadamente, período de la postguerra. Dialécticamente éste supone, en esencia, la identidad alcanzada al fin entre lo militar y lo político. Esta identificación queda recogida en el Acuerdo de Paz puesto que las partes beligerantes, no sólo muestran su conformidad y satisfacción por los compromisos alcanzados y los cumplen en un alto porcentaje, sino que también, mediante una reinterpretación histórica por la que afirman no haber abandonado ni traicionado los motivos y objetivos que los llevaron a la guerra, consideran que éstos se hallan en él contemplados. Según este discurso -que no por paradójico debemos apresurarnos a juzgar falto de sinceridad- las mismas motivaciones que inspiraron a uno $u$ otro bando y que provocaron el conflicto se mantendrían presentes e incluso estarían a la base de la configuración del Acuerdo de Paz.

Ello.es expresión del momento dialéctico de la reconciliación en el que nos encontramos. En ella se reconcilian las partes y también lo que éstas en su esencia social y política representan. Lo superficial y débil de la reconciliación salvadoreña proviene no sólo de una cuestión de real voluntad de los actores, sino también de la transformación que éstos han hecho de sí mismos, devaluando con ello su propia naturaleza y representatividad social. Por otra parte, el proceso marca un nuevo momento en el que la dinámica política en su conjunto - no sólo en lo relativo a la esfera de la negociación - resulta devaluada en su importante rol, apartada de su posición de dominancia y determinación anterior, al igual que en su oportunidad lo había sido la dinámica militar. Se da también una reconciliación entre dos dinámicas antes enfrentadas, la militar y la política, pero irónicamente eso se da cuando ambas han perdido su relevancia en la determinación del proceso histórico global. 


\section{Dialéctica entre factor dominante y factor determinante}

puede apreciarse una evolución invertida entre las dos dinámicas que hemos considerado principales: la militar y la de diálogo-negociación. Ya antes señalábamos que la dinámica militar pasó, de tener un rol dominante, a ser factor determinante, para terminar finalmente en una posición subordinada; el elemento del diálogo-negociación, evolucionó inversamente, de ser inicialmente una dinámica subordinada a los requerimientos de la guerra, pasó a ser sub-dominante desde 1984, y posteriormente ascendería a una posición primero dominante, después codeterminante y por último determinante, apartando definitivamente al factor militar de su preponderancia anterior. Precisar más esta apreciación requiere que establezcamos cómo ha funcionado el juego dialéctico entre factor dominante y factor determinante.

Cuando una cierta dinámica determina en forma directa a las demás, en un papel de determinación en primera instancia, decimos que ésta se ha constituido en factor dominante del período. Son señales para distinguirlo el que se constituya en eje principal de la actividad, que múltiples coyunturas se configuren bajo su signo, que se erija por encima de las otras dinámicas, las cuales quedan sometidas a su mandato, y, por todo ello, que caracterice clara y sustancialmente el período. Llamamos factor determinante a aquél que ejerce como sobredeterminación o determinación en segunda instancia, el cual habrá tenido influencia decisiva en que haya sido una u otra dinámica la que ascendiese como factor dominante. Con ella se complementará primero, pero entrará después en tensión dialéctica. Un tercer elemento fruto de la contradicción dialéctica entablada entre factor determinante y factor dominante aparecerá como factor sintesis o, dicho más precisamente, como "negación de la negación", en tensión contradictoria con los dos primeros. Cabe advertir que no debe confundirse nuestra definición de la categoría teórica "factor determinante", con el uso que se le ha dado al término desde el planteamiento marxista sobre el carácter determinante del elemento económico, el cual, según el propio Marx, debía entenderse como factor determinante "en última instancia".

Consideramos que a lo largo de la década de los setenta la fuerte 
conflictividad social-herencia del fracaso que tuvo el MERCOMUNCA y consecuencia también de la guerra con Hondurassobredeterminó la polarización y politización extremas de la sociedad salvadoreña, lo que a su vez generó un fenómeno de sobreideologización. Aparece la dinámica social como factor determinarite, la política como factor dominante y como elemento síntesis del período la ideológica. Esta será la nueva tesis o primer elemento en la tríada dialéctica de la siguiente fase (1979 a 1990) en su carácter de factor determinante. Factor dominante, ejerciendo una determinación en primera instancia sobre las demás dinámicas, será el componente militar; la militarización de la política presidirá los tiempos a lo largo de los ochenta.

Ahora bien, de la tensión dialéctica entre ellos surgirá a lo largo del período el elemento político, bajo la forma de política de diálogo-negociación, como elemento sintesis. Desde el punto de vista de ese resultado puede calificarse de etapa de gestación de la solución negociada a toda la década, caracterizada antes como de guerra total y de guerra integral. El conflicto bélico nos aparece entonces como una etapa generadora de la paz actual, puesto que el período invierte sus términos y niega al final lo que fue su punto de partida. Lo militar había desarrollado su contradicción con el factor determinante de la sobreideologización. Efectivamente, la guerra exige fuertes dosis de realismo, e incluso pragmatismo, que obligan a superar los dogmatismos ideológicos. También la dinámica de la negociación vendrá a rechazar dicho elemento, a la vez que se enfrenta al militarismo prevaleciente. Este elemento tercero, como "negación de la negación" consumará la negación de ambos, tanto del factor determinante como del dominante, postulando afirmativamente la desideologización y la desmilitarización. De esta forma podemos observar cómo al desarrollar la guerra sus protagonistas estaban en realidad gestando la paz. La lógica dialéctica de la historia se impone al fin a la disposición confrontativa de los actores - sin forzar su voluntad sino desde su propio impulso- hasta llegar a negar el signo bélico de los tiempos y abrir un nuevo período con signo contrapuesto.

Consideraciones para una historia de la paz

L a segunda mirada al período que estudiamos constituye una 
en 1994 y "posicionada" a favor de la paz, elemento sustancial de nuestro tiempo actual y horizonte promisorio hacia el que se orienta hoy la voluntad y esperanza colectivas. Desde esta perspectiva, superadora del nivel interpretativo anterior, nuestra búsqueda se ha dirigido a estudiar los procesos que hicieron posible, en el marco de la guerra, el despliegue silencioso de su contrario dialéctico, hasta que del conflicto bélico surgió al fin la paz, de la confrontación militar la concertación política entre las partes beligerantes, de la.lucha por intereses clasistas, ideológicos o sectoriales un mínimo consenso nacional a favor de la estabilidad y la gobernabilidad. Revelar el movimiento dialéctico fundante de la solución negociada ha centrado nuestro esfuerzo por re-construir una "historia de la paz" en El Salvador. Esta nos parece esencial para cimentar una conciencia lúcida del proceso y potenciar que el Acuerdo de Paz se constituya en una auténtica "primera piedra" sobre la que empezar a edificar un mejor futuro.

El "hilo" que debemos seguir en este nivel interpretativo es el de la dialéctica entre las dos partes en conflicto, la relación entre dinámica de negociación y de democratización y la establecida entre las políticas de ambos bandos respecto la negociación. De tal modo, incluiremos en nuestro estudio no sólo las rondas de diálogo y las sesiones negociadoras, sino asimismo los lapsos temporales entre unas y otras reuniones, así como el período previo al primer encuentro entre las partes, puesto que incluso las más elementales posiciones respecto la posibilidad o no de una solución negociada expresan ya una política al respecto. Desde este enfoque entenderemos que el proceso de paz, considerado en toda su amplitud, se inicia al mismo tiempo que el conflicto armado, por lo que nuestra elaboración de una historia de la paz no va a partir de la instalación de la mesa negociadora en abril de 1990, ni tampoco del primer diálogo el 15 de octubre de 1984, sino que se remonta hasta más atrás, hasta 1979, cuando estalló la guerra civil en el país. Nos proponemos darle seguimiento atento a dicho proceso, que globalmente tiende hacia la paz, tratando además de profundizar en él desde la lógica dialéctica que venimos utilizando, por lo que el discurso expositivo mostrará ciertos paralelismos con el análisis que desde una historia de la guerra hemos dibujado. 
La primera precisión que debe hacerse es sobre la diferencia entre estas categorías, diálogo y negociación, aunque algunos en el lenguaje común hayan usado ambos términos como sinónimos. En la negociación encontramos una voluntad de llegar a "resultados concretos" y de medir su avance en función de ellos, la cual falta en el simple diálogo. Este puede resultar exitoso, desde el punto de vista de las partes, aún cuando no haya obtenido ningún acuerdo. Podría decirse que el objetivo que el diálogo persigue queda afuera de sí mismo. Ello es así porque, en esencia, con quien cada parte dialoga no es tanto con la contraparte, como con otros que no están sentados a la mesa de conversaciones: aliados políticos, gobiernos amigos, instituciones internacionales, la población salvadoreña, la comunidad internacional, etc. Pero en la medida que el diálogo ha quedado instalado y se desarrolla tenderá a superarse este primer nivel puramente dialógico y se establecerá una relación dialéctica en el proceso de conversaciones entre ambas partes.

La negociación significa un nivel cualitativamente superior, puesto que ella contiene su propio objetivo. Mientras podía tener un sentido buscar el diálogo por el diálogo mismo, esperando obtener ciertas metas o determinadas ventajas con el sólo hecho de aceptar sentarse a dialogar con la contraparte, eso ya no será posible en la negociación. Esta consiste en un intercambio, donde cada bando cede y a la vez gana; en último extremo, se trata de un contrato cuyos términos deben ser acordados. Ya no basta a las partes con mostrar disposición y buena voluntad, se ha vuelto para ambas imperativo el llegar a acuerdos, si no quieren cargar las dos con los costos políticos de un fracaso. Nos interesa en nuestro análisis observar el paso de un nivel puramente dialógico a una auténtica dialéctica en el diálogo entre las partes, y el salto cualitativo al nivel superior de la negociación.

Debemos también poner atención a un problema que, si es visto superficialmente, podria parecer trivial: ¿quiénes son las partes? La cuestión no se presenta tan simple como parece si recordamos que queremos examinar su comportamiento a lo largo de los quince años objeto de nuestro estudio y no solamente en los escasos dos años que duró el proceso de negociación. Enfocado así, vemos que el asunto es más complejo de lo que podía parecer, puesto 
que la composición de las partes es múltiple, variable y también sus componentes cambian. Tanto del bando gubernamental como del lado insurgente, cada parte actúa como un solo actor, pero en realidad incluyen a varios actores políticos. Es el caso de las distintas instancias estatales representadas en la mesa por el Poder Ejecutivo, y también de la alianza FMLN-FDR, que incluía a nada menos que 8 actores.

Se daba además una variación evidente en el caso del gobierno. Este pasó de las primeras Juntas que eran expresión del pacto democracia cristiana/Fuerza Armada a la abigarrada mezcla de la presidencia provisional de Alvaro Magaña, después vino la gestión del cristiano-demócrata Napoleón Duarte y finalmente la presidencia del líder de ARENA, Alfredo Cristiani. También en el otro bando había cambios en sus componentes a partir del retorno a $\mathrm{El}$ Salvador de los líderes del FDR y la transformación de éste en la legalizada Convergencia Democrática la cual ya no participaría en la dinámica de diálogo-negociación. Sin embargo, cambiaban las partes pero no se alteraba la sustancia del todo, y prevalecía la continuidad en el proceso. Este proseguía sin truncarse, según su propia lógica, dándose el fenómeno de la acumulación que es caracteristica de todo proceso, confiriéndole una coherencia sorprendente. Esta cuestión viene a poner de relieve la presencia de aspectos estructurales que no aparecen en un primer plano. Por ellos se configuran dos bloques históricos que son expresión de la situación nacional, desgarrada por la lucha de clases, de la cual las partes beligerantes son sólo su reflejo y encarnación.

\section{Evolución de la dinámica política}

F $\mathrm{n}$ el movimiento general que preside el proceso se dan variadas formas de interacción entre las partes enfrentadas. Un primer mecanismo al que podemos ya considerar como expresión de una interacción actuante, es el de la cooptación -entendida como apropiación- de planteamientos y componentes del proyecto $\mathrm{y}$ propuestas del adversario. Así, un elemento central del pacto entre el PDC y la Fuerza Armada fue la incorporación en el programa de la segunda Junta de Gobierno de una parte sustantiva de las medidas de mediano plazo o "cambios estructurales" que planteaba la "Plataforma del Gobierno Democrático Revolucionaro", 
GDR. La realización en la práctica por la alianza militares/democracia cristiana de reformas profundas al sistema socio-económico, que constituían la médula del programa revolucionario, podría según el cálculo de los líderes reformistas y de sus aliados estadounidenses- dejar sin rumbo y sin razón de ser a la opción histórica que encabezaba el FDR-FMLN.

Ese filo marcadamente contrarrevolucionario del programa de reformas sería confirmado por el propio presidente Duarte años más tarde cuando en la presentación de su propuesta en La Palma en 1984, señalase al FDR que éste continuaba "tratando de cambiar algo que ya no existe". El intento de generar el desconcierto estratégico en la parte contraria se hacía explícito en expresiones de Napoleón Duarte como la siguiente: "Les digo... a los ideólogos de la subversión armada salvadoreña que revisen sus estrategias frente a la nueva realidad del pais". Las reformas estructurales reforma agraria, nacionalización de la banca y del comercio exterior-, realizadas en el marco de la contrainsurgencia, difícilmente podían conservar sus esenciales rasgos antioligárquicos, antimilitaristas o antiimperialistas, cuando eran llevadas a cabo justamente en alianza con la Fuerza Armada y el imperialismo, en una estrategia que era asimismo compartida por el sector más modernizante de la oligarquía.

No obstante, las reformas eran un hecho, y no podía obviarse fácilmente la realidad de su contenido, su profundidad inicial y la radicalidad con que fueron, en un principio, levadas a cabo. Por ejemplo, para muchos analistas independientes, la reforma agraria salvadoreña era una de las más completas llevadas a cabo en América Latina. Efectuada sorpresivamente -en una misma noche el ejército se tomó todas las grandes propiedades afectadas- y con indemnizaciones muy inferiores al valor real de las mismas usando el truco de pagar el valor con que el dueño tuviera inscrita para efectos fiscales su propiedad- no podían, con un mínimo de objetividad, ser criticadas como medidas cosméticas o superficiales.

Puede ser significativo, para ver la dificultad que las reformas de la segunda Junta causaron a la oposición insurgente, el que, en las tres propuestas de diálogo hechas por el FDR-FMLN entre 1981 
y 1983, no se haga mención a este punto. En el Programa del GAP era lógicamente obligado, el que los Frentes se pronunciaran al respecto; ahora bien, llama la atención que, a pesar de que en el documento se calificaba a la sociedad salvadoreña de "sociedad oligárquica" y se señalaba que "el Estado está a su servicio", respecto a las reformas económico-sociales solamente se planteaba la necesidad de su realización "plena", sin aclarar qué es lo que, a juicio de los Frentes, le faltaba a las mismas. En realidad, no sería sino hasta después de que el PDC hubiese sido desplazado del gobierno, tras las elecciones presidencales de 1989, que la insurgencia salvadoreña encontraría una política más coherente hacia las reformas estructurales, condenadas anteriormente por "contrainsurgentes"; reivindicaría entonces su defensa y la de la red de asociaciones cooperativas que ellas generaron, frente al intento de ARENA y la oligarquía de revertirlas y anularlas.

No se piense, sin embargo, que solamente la democracia cristiana utilizó el mecanismo de la cooptación; ARENA, el partido más alejado ideológicamente del FDR-FMLN, empleó, desde el momento mismo de su fundación, un procedimiento análogo. La intencionalidad es siempre muy difícil o imposible de demostrar, pero una probabilidad razonable debe bastar al analista: resulta demasiada casualidad que aparezcan como lema de ARENA los mismos términos que figuraban como metas del GDR. En él se postulaba por asegurar la paz, la libertad, el bienestar y el progreso social, mientras la formación política ultraderechista haría de PAZ/PROGRESO/LIBERTAD su lema partidario. Más adelante, durante el mandato del presidente Alvaro Magaña, la palabra "bienestar" -la otra meta del GDR - apareceria asimismo vinculada al régimen, dándole nombre a uno de los operativos de contrainsurgencia de la nueva concepción "de baja intensidad": el plan político-militar "BIENESTAR para San Vicente".

Es en esa forma que puede observarse cómo la disputa ideológica incluía el intento de arrebatarle banderas, metas y principios doctrinarios a la contraparte. La posición insurgente de negarle cualquier legitimidad a la contraparte - tal como se expresaba en octubre de 1981 - era, probablemente, una respuesta al esfuerzo gubernamental por recuperar la institucionalidad del Estado, anulada parcialmente por el golpe militar del 15 de octubre, y por 
superar la posterior situación "de facto" en la que se gobernaba por decreto. Los Frentes reaccionaban negando, en principio, cualquier credibilidad a dicho proceso de institucionalización. Esa actitud estaría todavía presente en enero de 1984, en el planteamiento del GAP, cuando la institucionalidad naciente, impulsada por el gobierno, se había desarrollado considerablemente y comprendía incluso una nueva Constitución, aprobada el año anterior, la cual no sería analizada y criticada en su contenido concreto por los Frentes, sino simplemente rechazada en su globalidad.

Llama la atención que el documento del FDR-FMLN prácticamente viniera a plantear la creación de un gobierno "de facto", el cual debería surgir del acuerdo entre las fuerzas políticas que participasen en la solución negociada. Había una simplicidad excesiva de los Frentes respecto al fenómeno institucionalidad: en los órganos previstos para el GAP desaparecía la Asamblea Legislativa y, por tanto, cualquier expresión parlamentaria; los Frentes planteaban derogar la Constitución de 1983 y que el GAP se rigiera por un "Estatuto Constitucional", supuestamente dictado por el nuevo poder emergente; exigían, no sólo la disolución de los cuerpos de seguridad y de los escuadrones de la muerte, sino también "de su brazo político, el partido ARENA", o sea, disolver un partido político.

No sería sino hasta muy tardíamente, durante la negociación propiamente dicha, que la insurgencia demostrase un manejo de altura y muy creativo del fenómeno institucional. En resumen, la interacción que estamos estudiando pasó por distintos momentos: ya hemos visto la cooptación gubernamental del programa de reformas planteado inicialmente como parte del programa histórico de la insurgencia; después, frente a las acusaciones de ilegitimidad del régimen, éste se adentró en el proceso de institucionalización estatal; la interacción proseguiría después a través del mecanismo electoral y de las iniciativas de amnistía mientras la otra parte insistía en presentar nuevas propuestas de diálogo-negociación.

\section{Dialéctica entre las dos partes en conflicto}

$\mathrm{M}_{\text {ientras en la historia de la guerra nos habíamos referido en }}$ sujetos sociales, para la historia de la paz vamos a partir de la 
relación entre las dos partes beligerantes. Son básicamente ellas las que, en su contradicción y en el movimiento de superación de tal lucha de contrarios, cualificarán el proceso haciéndolo pasar de la confrontación a la conciliación. Cada bando necesitaba acompañar y complementar su estrategia de guerra con una determinada política. El diálogo-negociación se constituyó en la política de la estrategia insurgente, mientras la re-institucionalización del Estado, las elecciones y la democratización se convertían en la política de la estrategia contrainsurgente. Esta contraposición entre negociación y elecciones sería una constante a lo largo de todo el conflicto, constituyéndose cada una de dichas opciones como la justificación o "la política de la guerra" de cada una de las partes. Ese esquema expresa el eje principal en torno al cual giraría la dinámica política en la disputa entre las contrapartes.

Los Frentes presentaron su primera propuesta de negociación recién en 1981, la cual sería reiterada con ligeras variantes en ese mismo año y el siguiente, sin que la parte gubernamental diera otra respuesta más que el simple rechazo. Las elecciones de 1982, presentadas por el gobierno salvadoreño, la Organización de Estados Americanos, OEA, y Estados Unidos, como "la vía de solución al conflicto", jugaron desde su anuncio el papel de una alternativa al mecanismo negociador propuesto desde 1981 por la alianza FDR-FMLN. Volvería a haber elecciones en 1984, otra vez en 1985 y nuevamente en 1988 y 1989, mientras la guerra no sólo continuaba sino que se recrudecía. Los Frentes no conseguian presentar una respuesta coherente ante el planteamiento electoral, cuya sola realización constituía en sí un pequeño triunfo para su contraparte. Tal como analizaba el doctor Ellacuría, "el FDR-FMLN ante la maniobra política de las elecciones, ofrece la maniobra política de la negociación". Pero esa respuesta era en sí insuficiente: la insurgencia poco a poco perdía imagen y también, paulatinamente, implantación popular. "Parecería -advertía el mencionado jesuita- que en el FDR-FMLN hubiera una visión distorsionada de lo que está ocurriendo en el sentir de una parte mayoritaria de la población". Es decir, aunque el mecanismo electoral resultaba ineficaz para resolver el problema principal - la guerra - no por ello era inútil en su propósito de autolegitimar la opción gubernamental y debilitar políticamente a la insurgencia. 
Algo parecido ocurriría con las leyes de amnistía, repetidamente decretadas por los sucesivos gobiernos. La primera de ellas fue iniciativa del gobierno de Alvaro Magaña, quien, a poco de asumir la presidencia en 1982, decretó una ley de amnistía para los alzados en armas. Reaccionaba así al dilema planteado por la insurgencia -o solución negociada, o salida militar - con su propio dilema: o incorporación a la vida política desarmada, mediante el amparo a la amnistía, o la guerra y la solución militar. Quien probablemente interpretó más claramente el sentido verdadero de la referida "Ley de Pacificación, Amnistía y Rehabilitación Ciudadana" fue Roberto d'Aubuisson, a la sazón Presidente de la Asamblea Constituyente: "si los subversivos no aceptan esta oportunidad, no habrá otra solución más que la militar..."

En realidad, tanto con los decretos de amnistía como con las ofertas de negociar espacios políticos legales para las fuerzas agrupadas en el FDR, el régimen pretendía mostrar una falsa flexibilidad, dado que ésta se reducía a quienes aceptaran separarse de la opción revolucionaria, representada por el FMLN. De ahí el nulo resultado de ambas políticas, demasiado evidentes en su propósito contrainsurgente, pues ni las amnistías conseguían en la práctica un aumento sustancial en las deserciones de las filas guerrilleras, ni la disposición gubernamental a negociar la participación electoral del sector más moderado de la alianza rebelde, generaba en los partidos del FDR mayor eco. No sería sino en una coyuntura muy posterior, en plena "politización de la guerra", cuando éstos reingresarían a la política activa en el país acogiéndose al marco de legalidad, pero sin renunciar de hecho a su alianza con las fuerzas alzadas en armas. Veamos antes el sentido de la evolución general del proceso.

Dialéctica entre política de negociación y política de democratización

【a relación dialéctica entre ambas políticas nos mostrará un nueLvo ángulo de la evolución del proceso. Se desarrolla entre ellas una oposición de contrarios que toma una forma similar a la que en la historia de la guerra habíamos visto que adoptaba la dialéctica entre dinámica militar y dinámica política. Efectivamente, en la primera fase encontramos que predomina la contradicción absolu- 
ta, la exclusión, entre la política de negociación y la política de democratización. Ambas partes niegan en ese tiempo toda validez y cualquier credibilidad al planteamiento del adversario. En un caso, argumentando una voluntad engañosa en las ofertas de diálogo de los rebeldes - los que, según la versión gubernamental, sólo pretenderían ganar tiempo para hacerse con todo el poder-; del otro lado, calificando de "cosméticas" y de "pura propaganda" las medidas estatales democratizadoras y rechazando el que éstas pudieran significar ningún cambio sustancial en un régimen que, a los ojos de los insurgentes, era en su esencia dictatorial y terrorista.

El simple rechazo a la posición del contrario empezó a verse superado en la segunda fase, cuando una vez instalado el diálogo éste obliga a oir y a dar respuesta al planteamiento adversario. En las pláticas del proceso de diálogo lo que básicamente cada parte hacía era exponer sus propias posiciones, argumentarlas y tratar de rebatir los razonamientos del contrario. Ello no debe llamarnos a engaño: en este nivel no se argumenta para convencer, sino sólo para influir. Al igual que ocurre en la diplomacia, en este diálogo político la finalidad de la discusión no es convencer al interlocutor. El interés no está en atraerlo y ganarlo para nuestro bando; al revés, la intención última es que siga siendo contraparte, que permanezca identificado con nuestro adversario y como representante suyo pues, de lo contrario, lejos de ser un éxito, el diálogo sería una pérdida de tiempo. Por tanto, se quiere que el otro "salga como entró", y al mismo tiempo se trata de que -influenciado por nuestro discurso y nuestros argumentos- "no salga exactamente igual a como entró". Inconscientemente se busca, pues, alcanzar la dialéctica entre la identidad y la diferencia que expusimos anteriormente, la cual ya explicamos que tiende a una identidad superior entre la identidad y la no-identidad.

En este desarrollo ambas partes se influenciaban mutuamente. El Frente deja de considerar el mecanismo de las elecciones como una concesión a ofrecer durante la negociación y pasa a concebirlas como un componente sustancial de su programa. También desde el gobierno se empieza a admitir lo limitado de la democratización y que ésta no podrá ser completada sino una vez resuelto el problema central de la guerra y después de que se hayan integra- 
do al sistema los alzados en armas. De ahí que la dialéctica entre la negociación y la democratización tienda a desarrollarse en esta fase bajo la forma de una paradoja: ambas se necesitan pero al mismo tiempo se excluyen. Posteriormente, se volverá más acusado lo paradójico de la relación entre ambas políticas, presentándose como un dilema: o se opta prioritariamente por la una o por la otra. Es decir, o los rebeldes se insertan en el proceso de democratización eludiéndose así — por innecesaria - la negociación, o, por el contrario, será la negociación la que se encargará de lograr imponer la democratización real.

Finalmente, en la fase de la negociación se alcanzará el nivel de la identidad o identificación entre ambas políticas, constituyéndose así el Acuerdo de Paz en un punto de arranque, no sólo de un verdadero proceso de pacificación sino también de la auténtica democratización. Esta es concebida de forma tal que incluye la negociación como uno de sus mecanismos esenciales, e inversamente, la construcción de la democracia real es vista como parte sustancial de la solución política negociada. El régimen - por medio de su más cualificado representante, el Presidente de la República, Alfredo Cristiani- termina aceptando que en el pasado no ha habido real democracia en el pais y que ésta fue una de las causas principales del conflicto. Es la reconcilicación última entre política de negociación y política de democratización, quedando en ella así representada la reconciliación entre las partes beligerantes.

\section{Dialéctica entre las políticas de negociación de cada parte}

$\mathrm{D}$ esde la historia de la paz vamos a construir una segunda periodización que contará con lógica y ritmo propios, aunque la secuencia sea parecida a la que estructuramos al desarrollar el esquema de la historia de la guerra. Hablábamos antes de períodos, mientras ahora llamaremos fases a la división temporal del proceso, con el único objeto de distinguirlas etimológicamente de aquéllos. En los dos casos nos aparecen cuatro saltos dialécticos que determinan cinco lapsos temporales. Aunque el momento del corte periodizador entre unos y otros sea aproximadamente el mismo, no se trata de un simple "llamar distinto" a lo igual, sino que en esencia estamos ante una nueva periodización, que necesitamos para calificar adecuadamente la secuencia propia de la espe- 
cial lectura analítica del proceso que estamos ahora abordando. De tal forma encontramos que la historia de la paz aparece desarrollada en las siguientes cinco fases: de pre-diálogo (desde 1979 hasta 1983), de diálogo (de 1984 a 1988), de pre-negociación (1989), de negociación (1990 y 1991), de post-negociación o proceso de paz o, también, fase de cumplimiento de los acuerdos (de 1992 a junio de 1994).

En la fase de pre-diálogo (coincidente en el tiempo con lo que antes habíamos llamado período de guerra total) se dieron diversas iniciativas de las partes, principalmente del lado del FMLN y FDR, los que presentaron varias propuestas. En esencia no se trata tanto de una preparación al auténtico diálogo, como de la existencia de dos monólogos contrapuestos. Ninguna de las dos partes aceptaba en ese tiempo alguna legitimidad a la contraparte; en el lenguaje de la época unos eran "delincuentes terroristas" mientras los otros eran calificados de "gobierno ilegítimo y sanguinario". Desde el Estado ni siquiera se reconocía la existencia del conflicto civil en cuanto tal, según un discurso por el que en El Salvador no había sino simple bandolerismo e intervención de potencias extranjeras y del comunismo internacional; mucho menos era aceptada la condición beligerante de la oposición armada, su carácter de fuerza interna organizada o la representatividad que detentaba respecto sectores de la población que se identificaban con su proyecto histórico.

Esta muy ideologizada intransigencia no podía mantenerse por tiempo indefinido, dadas las presiones nacionales e internacionales a favor de la apertura del diálogo, así como por el interés de la propia dinámica global, pues a cada parte convenía políticamente reforzar su propia legitimación. De esa manera se abrió la nueva fase de diálogo, en la que ambas partes dejan de des-conocer a la otra $y$, en el hecho mismo de sentarse frente a frente en la mesa de conversaciones, pasan a reconocer su existencia como contraparte. El objetivo de la propia legitimación no podía ser logrado sino concediendo al mismo tiempo cuotas de legitimidad al enemigo. La discusión mantendrá por mucho tiempo características de un doble monólogo, pero, una vez iniciada, la dinámica dialógica impondrá lentamente su movimiento. Por él tenderá a transformarse en una dinámica dialéctica entre las partes, en la que los interlocu- 
tores identificarán áreas y problemas específicos donde, pese a sus esenciales diferencias, hallarán coincidencias y aspectos cuya resolución es de interés común.

Es de tal forma que las partes incluyen en su agenda puntos específicos sobre los que llegan a determinados acuerdos parciales; por ejemplo en lo relativo a intercambio de prisioneros, respeto a instalaciones hospitalarias y personal sanitario, medidas tendientes a "humanizar" la guerra y disminuir su impacto sobre la población civil, etc. El haber llegado a compromisos de esta índole y a su cumplimiento - siempre incompleto y difícil- no significa que el proceso haya entrado a la fase cualitativa de la negociación. Sigue estando presidido por el objetivo de reforzarse estratégicamente para la victoria militar. En ningún momento representa un avance hacia una salida política negociada; no es un preámbulo para la negociación mientras el objetivo último sigue siendo de naturaleza bélica, exterior a la dinámica de diálogo-negociación. Esto va a ser plenamente comprendido en la fase de pre-negociación, en la que los dos bandos están claros de que las medidas de humanización del conflicto, ni pueden realmente humanizarlo ni limitarlo, mientras formen parte de la estrategia de guerra de ambos. De ahí que brote con fuerza imperativa la necesidad de resolverlo de una vez por todas, terminándolo. Surge entonces como un dilema si acabar con la guerra por la vía militar o por la vía política, pues en el proceso de diálogo se ha comprobado que no son compatibles.

Después de ensayada y fracasada la opción de la ofensiva final se retomará la dialéctica del diálogo, valorizándose los aspectos positivos de dicha experiencia. El hecho de "haber negociado" en torno a concretos aspectos que no eran centrales, haber llegado a acuerdos al respecto y haberlos cumplido, aunque no propiciaba de por sí una salida negociada al conflicto, sí ha dejado demostrado de que son posibles acercamientos y compromisos entre las contrapartes. Por lo tanto, se ha abierto una brecha de credibilidad para un proceso serio de negociación global y definitiva. Al darse el salto cualitativo y entrar a la nueva fase de negociación, los contendientes no parten de cero, sino que tienen acumulado todo lo discutido y concertado en las fases anteriores, que por lo menos sirvieron para impulsar el conocimiento mutuo y generar grados 
de confianza entre ellas. Tanto por su contenido -que sustancialmente estriba en los objetivos y agenda a debatir - como por su procedimiento -ininterrumpido y con mediadores internacionales- esta fase significa cualitativamente lo nuevo: la disposición a no prolongar más sino a terminar con la guerra, a entrar mediante el proceso de negociación a concluir el conflicto.

Durante la negociación una nueva lógica va imponiéndose en la concepción de las partes. Mientras antes la actitud respecto al adversario era la de rechazarlo, ahora por el contrario se buscará atraerlo. Al enemigo ya no se pretenderá vencerlo en el debate, sino que se buscará ahora con-vencerlo, lo cual garantizará mejor el cumplimiento posterior de lo acordado. Se desarrolla entre las partes la comprensión, que implica un "incluir" en nuestros puntos de vista los del adversario y un "dejarse incluir" en los de él. La ex-clusión de la contraparte se ha convertido ahora en in-clusión. Mientras anteriormente cada bando pensaba sinceramente que tenía la razón y discutía con el otro desde esta convicción, ahora en cambio el argumentar se ha vuelto un razonar, que acepta que el contrario tiene sus propias razones, igual que nosotros las nuestras. Aceptar que cada parte tiene razones para su particular posición, significa admitir que - así en singular y en forma excluyentenadie tiene "la razón". La absolutización de las conciencias que presidía ideológicamente el movimiento de la guerra ha cedido el paso a la relativización, a la razonabilidad y a la flexibilidad, en la misma medida que se ha dado la superación de "la verdad" abstracta y absoluta - tras la que cada parte escudaba su propia parcialidad. Es por ello que el Acuerdo de Paz y su implementación representan el triunfo postrero de la razón positiva - la del concertar, del construir y del compartir- frente la razón negativa - la del desunir, destruir y disputar- que dominó el signo de los tiempos y la conciencia colectiva durante el conflicto.

En esta fase la realidad aparente es que las dos partes negocian entre ellas; sin embargo, se da otra negociación paralela y no visible al interior de cada bloque de fuerzas, que resulta por lo menos igual de decisiva que la primera. Efectivamente, cada parte debe consensuar posiciones entre los distintos actores que la integran, sus líderes civiles deben convencer a los jefes militares, los dirigentes del exterior ponerse de acuerdo con los del interior, habrá 
que compartir las decisiones con los aliados internacionales, etc. Es un intrincado y difícil recorrido el que cada nueva idea, propuesta o iniciativa deberá recorrer hasta conseguir el mínimo consenso para que sea aceptada, en el que no siempre la discusión con la contraparte resultará ser la más espinosa. La relación dialéctica entre las partes se refleja condicionada por una dialéctica interna, de cada parte relacionándose consigo misma. Es decir, a la par de la influencia recíproca de una parte respecto la otra se produce también internamente la transformación de ellas. Esta cuestión la examinaremos a continuación, al referirnos a la "historia de la democracia".

\section{Consideraciones para una historia de la democracia}

$R$ ecordando a Hegel en su forma de "decir" y de analizar la tóricos, en tanto que dialécticos, respecto al proceso salvadoreño podríamos por nuestra parte afirmar: los actores políticos, en su esfuerzo por transformar el país, se transformaron en realidad a si mismos. Con eso no queremos decir que no haya habido asimismo importantes cambios en la realidad del país, aunque se hayan dado sólo muy parcialmente según la idea y el sentido que pretendían las partes enfrentadas. Sin embargo, la transformación más profunda y efectiva la encontramos en los propios actores políticos, los que se veían a sí mismos como "agentes del cambio", sin que advirtieran lo tan profundamente que resultaban ellos mismos transformados. Desde una perspectiva filosófica este fenómeno no debería ser motivo de mayor extrañeza.

La vida es movimiento; todo lo vivo se transforma. Pertenece a su esencia la transformación y el movimiento. Mientras la materia inanimada, un objeto cualquiera, una piedra, por ejemplo, sufrirá alteraciones por causas que provienen de su exterior y por ello los cambios que experimente son para la piedra meros accidentes, en cambio el ser vivo, en cuanto sujeto, contiene dentro de sí mismo el principio de su movimiento y transformación. Lo accidental del acontecer cobra una menor relevancia en la medida que la dialéctica interna gobierna su movimiento más auténtico y profundo. Por éste dejará $\mathrm{A}$ de ser idéntico a si mismo, transformándose continuamente, en un movimiento que es su propia negación, convir- 
tiéndose en no-A. Para citar un ejemplo clásico: el capullo se convertirá en flor y ésta en semilla; la "verdad" de la planta, su realización, está en este movimiento de negación, en el conjunto del mismo y no en uno cualquiera de sus momentos. Para seguir existiendo, para poder seguir siendo A, lo vivo precisa de ese movimiento que lo lleva a un no-A, es decir, alcanza su propia afirmación sólo a través de su negación. El niño que re-niega de su ser niño y busca su esencia en llegar a ser adulto, expresa con ello su realidad de niño; la realidad del sujeto se confunde entonces con su realización como sujeto. Esa consideración dialéctica general cobra mayor entidad cuando se trata, no de un sujeto vivo cualquiera, sino del sujèto humano, y aún más evidente cuando la aplicamos referida a un sujeto colectivo, como es nuestro caso.

¿Cuáles son los opuestos dialécticos cuya tensión provocará el movimiento interno que hemos señalado? En su nivel más abstracto, lo que últimamente entra en tensión dialéctica interna es algo que aparece con carácter básicamente ontológico: de un lado el ser, lo que el sujeto "es", lo que al sujeto lo define; del otro lado está su actividad, lo que el sujeto hace, lo que al sujeto lo conforma. En último extremo la contradicción dialéctica se establece entre la realidad del sujeto como esencia y su realidad como existencia. En esa relación dialéctica la preeminencia pertenecerá al segundo de los términos, siendo su realidad en el existir y en el actuar la que pre-dominará sobre la esencia del sujeto, transformándola y transformándolo. Es a partir de esta consideración que cobra plena significación la idea de Hegel: "nos transformamos en el curso de nuestro esfuerzo por seguir siendo nosotros mismos". Desde ella nos podemos ahora plantear la pregunta -central para comprender nuestro proceso como internamente orientado hacia la democracia- que hace referencia a la autenticidad de la "conversión democrática" de las partes beligerantes.

Estas, desde el punto de vista de su esencia, históricamente han correspondido a determinados intereses clasistas, colocados en un primer plano a partir de la agudización de la crisis nacional. Los actores políticos son pues "esencialmente" reflejo y representación de los sujetos sociales. El "ser" de las partes se ha visto constituido básicamente mediante un proceso de toma de conciencia. De tal concientización social, surgió un proceso de identificación polí- 
tica con características de masividad, que convirtió a los actores en auténticas fuerzas políticas, con identidad propia y unidad de propósito. Pero desde el punto de vista de su existencia, de su papel y actividad en el proceso histórico, los actores son tales porque actúan. Es en la acción concreta donde encuentran su verdadera conformación. Como entes políticos existentes privilegian el compromiso militante, el activismo político, la participación efectiva en el accionar. Desde la praxis, la unidad interna de las partes se revela sustancialmente como unidad de acción.

Vistos teóricamente los actores son sólo representantes de clases y sectores sociales, y su lucha sólo el reflejo superestructural de la lucha real existente entre clases contrapuestas. Pero considerados prácticamente los actores tienden a actuar como sujetos, suplantando en parte a las clases que representan y a la vez configurándolas en su misma práctica. La contradicción aparece como contraposición entre teoría y práctica, como tensión dialéctica entre unidad de concepción y unidad en la acción, como oposición de contrarios entre la conciencia que identifica y la lucha común que unifica. En esa dialéctica - coinciden Marx y Hegel- la primacía corresponde a la praxis, a la acción y a la lucha. Por tanto, lo que en el proceso resultará modificado es la teoría, la concepción y la conciencia La negociación y el Acuerdo de Paz como realidades fácticas demuestran, una vez más, la verdad de la idea marxiana de que "no es la conciencia la que determina la realidad sino, inversamente, la realidad social es la que determina la conciencia".

Desde la dialéctica entre la conceptualización y conciencia de las partes y la realidad de su práctica política, nos interesaremos por las transformaciones internas acaecidas en la esfera ideológica a lo largo de esos quince años. Los cambios de naturaleza político-ideológica son los que nos permitirán entender la conversión de los antiguos "señores de la guerra" en los actuales "paladines de la paz". El pensamiento negociador evolucionó desde un rol puramente subordinado y secundario hasta posicionarse en un lugar central y determinante. Logró así permeabilizar el pensamiento político y la ideología, alterando la esencia misma de los actores. Se verán entonces modificadas sus concepciones, sus metas y objetivos. La lucha por el poder apareció a su término convertida en una lucha por la democracia. El intento de derrotar militar- 
mente al contrario se trocó en empeño por construir conjuntamente con él un nuevo escenario -democrático- en el que el adversario pasa a ser visto como necesario e indispensable, como una contraparte a la que se buscará derrotar en la arena política, pero a la que se acepta y que debe, asimismo, ser preservada. En El Salvador la "historia de la democracia", aunque totalmente incipiente en su despliegue, no por ello es menos real. Preside dinámica y contradictoriamente la nueva etapa en que nos encontramos hoy, un tiempo de transición que estamos empezando a recorrer y cuyo desenlace futuro es todavía una inquietante incógnita.

\section{Evolución de la dinámica ideológica}

Dara poder examinar con más detalle el camino recorrido por la lifica a la concepción negociadora, nos vemos precisados primero a definir algunas categorías que nos son imprescindibles para ello. En primer lugar: la ideología. En general, los especialistas no se ponen de acuerdo a la hora de formular una definición - no ideológica- de la ideología política. Para Weidle la ideología difiere de la filosofía por no incorporar la "Weltanschauung" (visión de mundo); la identifica con la doctrina cuando, citando al Larousse, suscribe la siguiente definición de ideología: "sistema de ideas que constituyen una doctrina política o social y que inspira los actos de un gobierno o de un partido." Igualmente procede Aron, quien emplea ambos términos como sinónimos, o utiliza el recurso de referirse a "las doctrinas ideológicas". Mayor precisión conceptual demuestra Chevallier, para quien ideología consiste en "un sistema coherente $u$ organización de ideas, de representaciones intelectuales, susceptibles de determinar en una cierta dirección el comportamiento humano"; este concepto según el autor incluye también "un sistema implícito de valores".

Para nuestros propósitos importa distinguir claramente entre estos distintos componentes, por lo que no nos satisface ninguna de las definiciones citadas. Tampoco nos ayuda mucho suscribir la clásica formulación marxista sobre la función encubridora y distorsionadora de lo real que posee la ideología. Más bien nos interesa la función "positiva" de la ideología política en tanto necesaria, indispensable para la acción histórica y eficaz en su rol 
aglutinador y movilizador. De Marx preferimos pues retomar su consideración de que la ideología puede, en determinadas condiciones históricas, transformarse en "fuerza material". Adoptaremos, por tanto, una definición positiva de ideologia. La definiremos como "un conjunto de ideas y representaciones políticas, vinculadas'entre si por un sistema de valores y una determinada visión de mundo".

De tal modo, estamos postulando la vinculación entre ideología y clases sociales, en tanto éstas tienden a desarrollar su propia concepción de mundo, por lo que hablaremos de ideología burguesa, obrera, campesina, etc. También, desde el énfasis en los sistemas de valores, encontraremos ideologías de izquierda y de derecha, conservadoras y progresistas, revolucionarias y reaccionarias, etc. La complejidad de lo ideológico vuelve inútil cualquier estricta clasificación. Será por ejemplo posible hallar revolucionarios con mentalidad conservadora, al igual que reaccionarios con actitudes progresistas; podremos detectar en cierta izquierda rasgos de conservadurismo, así como posturas progresistas en sectores del bloque de derechạ. El dogmatismo lo consideramos como un momento que se puede presentar en todo discurso ideológico, pero al cual la ideología no se reduce, ni supone éste su momento más representativo. La fluidez de un pensar vivo acepta el reto de su desarrollo propio y no será sino en la fosilización del pensamiento cuando éste se endurezca, cristalice, en la forma inamovible e incuestionable del dogma. La crítica al dogmatismo no forzosamente deberia, pues, entenderse como "desideologización", una meta, por lo demás, históricamente inalcanzable.

Pasemos ahora a la doctrina política. Esta la podemos definir como "una elaboración ideológica por la que se pretenden justificar determinadas metas políticas y ciertos métodos de acción". A mitad de camino entre la ideología y las teorías políticas, la doctrina incorpora necesariamente ciertos valores previamente ideologizados. No hay doctrina política que no se encuadre en un determinado marco ideológico. No debe confundirnos el hecho de que afirmaciones de carácter doctrinario a menudo adopten la forma de un razonamiento. En realidad, la doctrina busca la adhesión más que la aceptación, la convicción más que el convencimiento. Tiende a rechazar la duda y el debate. Se acepta o no se acepta; si es aceptada deberá 
serlo integralmente, apasionadamente, vitalmente. De ahí que el llamado "adoctrinamiento" sea algo muy diferente al razonamiento teórico. Doctrinas políticas presentes en la historia salvadoreña reciente son, por ejemplo, el anticomunismo ultranacionalista, la doctrina demócrata cristiana, el marxismo-leninismo y el neoliberalismo.

Las teorias políticas significan "una elaboración doctrinaria en forma de planteamiento coherente de concepciones y razonamientos sobre la política, por la que se justifican determinados propósitos políticos y vias de obtención de los mismos". Las teorías políticas se referirán al Estado y la sociedad, a las clases sociales y los sistemas socio-económicos, al poder político y su ejercicio, etc. La teoría pretende independencia respecto los valores ideológicos y se abre al debate reclamando objetividad. En la discusión se ve sometida a pasar la prueba de la duda, de la verificación y de la posible refutación. Dependiendo de la solidez y coherencia interna de un determinado discurso teórico, éste puede mostrar sorprendente capacidad en "atrapar en su red" a quien siguiendo la lógica de su razonamiento, no consigue "salirse" para contestar desde su propia y distinta lógica teórica. El debate teórico aspira legítimamente, por tanto, sino a convencer, al menos a lograr un intercambio o una influencia con el interlocutor. Varias teorias pueden encajar en una misma doctrina. Para poner algunos ejemplos: de la doctrina demócrata cristiana surgió la formulación de la teoría del centro político "entre las dos extremas" y en pugna con ellas; del marxismo doctrinario, "los marxismos", o sea, su desdoblamiento en distintas teorías políticas sobre los propósitos y las vías de la revolución "proletaria" o "socialista"; del neoliberalismo, teorías sobre el papel "mínimo" del Estado, sobre el "libre" mercado y el ejercicio "democrático" del poder concebido como "representativo".

Bajemos ahora otro peldaño más para encontrarnos con la estrategia y las tácticas. Entramos aquí al reino de los fines y de los medios a emplear. La caracterización que hace $\mathrm{M}$. Duverger enfatiza el aspecto "previsión", identificando prácticamente estrategia con plan de acción: "En la lucha política... cada participante actúa de acuerdo con un plan preconcebido, más o menos elaborado, en el que se prevé no sólo sus propios ataques, sino también los contraataques del adversario, así como los medios para hacerle frente. Este 
plan de lucha constituye lo que se llama una estrategia, mientras que los diferentes elementos de que se compone se denomina la táctica." Preferimos formular con mayor precisión una definición de menor connotación militar y que nos diferencie con claridad lo que es la estrategia de lo que es la táctica. Proponemos considerar que la estrategia consiste en "la formulación de las tareas pendientes en una etapa histórica determinada y en la previsión general de las acciones prácticas a ejecutar, según un curso de desarrollo que se supone definido en sus grandes rasgos".

Definiremos la táctica como "la formulación de las tareas en un área o dinámica específica y para un período limitado de tiempo, en función de desarrollar una determinada estrategia". Mientras la estrategia significa una formulación de largo plazo y por tanto más general -aunque también más esencial - las tácticas se adecúan a las coyunturas concretas. Son por ello más flexibles y cambiantes, y, por estar referidas a esferas específicas de actuación, carecen del carácter globalizador que posee, por lo general, la formulación estratégica. La táctica, por definición, se adecúa a la estrategia a la cual sirve, lo cual no niega la influencia que determinadas tácticas puedan ejercer dialécticamente sobre la concepción general estratégica. Podríamos decir que la estrategia se realiza a través de las tácticas, las cuales se suceden unas a otras, al tiempo que pueden operar varias de ellas simultáneamente.

Por último, debemos referimos a las políticas: éstas suponen "lineas de acción para la concreción práctica y sistematizada de la concepción estratégica y de la táctica trazada, en un terreno concreto de la confrontación". Mientras los fines y los medios estaban ubicados al nivel de la estrategia y de la táctica, las políticas fijarán los objetivos alcanzables en una esfera determinada durante un periodo dado. Es decir, se encuadran en alguna de las dinámicas históricas, pudiendo éstas - como ya hemos visto- contener más de una política. Por otra parte, desde el punto de vista temporal, las políticas son muy sensibles a la coyuntura; tratando de incidir en ésta, a su vez se dejan moldear por ella. Valga decir que a efectos teóricos entenderemos por coyuntura "una determinada articulación de las distintas dinámicas del proceso histórico, que se mantiene durante un limitado lapso de tiempo". De tal forma, el proceso como secuencia de sucesivas coyunturas, es directamente afectado por la acción 
"cotidiana" de las políticas, pero éstas pagan el precio de tener que adecuarse convenientemente al ritmo coyuntural de aquél.

Pues bien, para definir el rumbo y evolución de la dinámica ideológica planteamos el siguiente procedimiento: examinar el papel desempeñado por la política de negociación a lo largo de todo el período, en su relación con los cinco niveles teórico-conceptuales que hemos definido. La hipótesis teórica que proponemos es que la política de diálogo-negociación se cualificó a lo largo de esos 15 años que estudiamos, "ascendiendo" los sucesivos "escalones" de la táctica, la estrategia, la teoría, la doctrina y la ideología. Son saltos dialécticos, por los cuales la negociación primero se ubica en una dimensión táctica (hasta 1983), después pasa a una dimensión estratégica (entre 1984 y 1988), en tercer lugar accede a la dimensión teórica (durante 1989), en un cuarto momento alcanza dimensión doctrinaria (en 1990 y 1991) y por último culmina escalando hasta la dimensión ideológica (de 1992 a 1994). Se estructura entonces una tercera periodización, propia de la "historia de la democracia" a que nos estamos refiriendo, con cinco etapas que se corresponden con los períodos y las fases que describimos anteriormente. Veamos a continuación la interpretación histórica que podemos extraer de esta hipótesis de trabajo, a la vez que trataremos de justificarla con los resultados que nos aporte el propio análisis.

\section{Dialéctica interna de las partes consigo mismas}

F $n$ una primera etapa las partes van configurando una política $\mathcal{L}$ de negociación que se mantendrá en una dimensión táctica. Es decir, al servicio de una estrategia de legitimación propia que, al mismo tiempo, persigue deslegitimar y aislar políticamente al adversario. Se procurará aparentar una voluntad pacífica mediante la política de negociación y denunciar una voluntad guerrerista en el enemigo. Se trata con ello, no sólo de justificar que se está empeñado en una guerra legítima, sino de apuntar también a que la misma es la única opción que ha dejado el contrario con su negativa a aceptar las propuestas negociadoras. De tal forma, la política de negociación juega un papel complementario a la política de alianzas, la cual busca neutralizar o atraer a amigos y aliados del adversario, así como pretende consolidar o ampliar el propio bloque de fuerzas. 
Los dos bloques se conforman entre 1980 y 1982 en un proceso de convergencia y unificación. De una parte surgirá el FDR-FMLN, tras la fundación de la Coordinadora Revolucionaria de Masas, CRM, y del Frente Democrático, FD, rápidamente transformados en FDR, Frente Democrático Revolucionario, mientras que la izquierda armada estructura la Dirección Revolucionaria Unificada, DRU, origen del Frente Farabundo Martí para la Liberación Nacional, FMLN. Al otro extremo, la crisis de los partidos tradicionales de la derecha está a la base del surgimiento del Frente Amplio Nacional, FAN, del cual surgirá la iniciativa de aglutinar en una alianza a las distintas corrientes contrarrevolucionarias gestándose la Alianza Republicana Nacionalista, ARENA. Por un lado se da dicha tendencia general a la unificación, del otro, lo que realmente se gesta es la división en dos bloques dramáticamente contrapuestos.

Los diversos partidos políticos del sistema confluirán, no sin una fuerte presión norteamericana, en una estrategia común a partir del Pacto de Apaneca, en agosto de 1982. En la dialéctica interior de las partes se ejercita la negociación, en función de lograr la necesaria coherencia interna para enfrentar mejor a su enemigo. En el FMLN tras una fuerte pugna, durante 1982 y hasta abril del 83, resulta aislada una posición que -desde una inspiración ortodoxamente leninista - quería generar un polo revolucionario dentro del bloque de fuerzas de la revolución, pretendía crear una vanguardia dentro de la vanguardia. Ello significa que también en el FMLN se impone la tendencia histórica a la unificación y a la negociación internas, frente a posiciones de mayor sectarismo y hegemonismo. Aún cuando sea con propósitos totalmente contrarios a la solución negociada, el ejercicio de la negociación -en tanto ésta es también un mecanismo y una técnica política- deja un sedimento de habilidades políticas y de "experiencias negociadoras" entre los actores políticos que componen las partes beligerantes.

En 1984, con el planteamiento por la insurgencia del Gobierno de Amplia Participación, GAP, pero principalmente a partir de la propuesta hecha por el Presidente Napoleón Duarte en La Palma y de la contrapropuesta rebelde en Ayagualo, la política de negociación accede a la dimensión estratégica. Esta etapa se extenderá 
hasta fines de 1988, correspondiendo temporalmente al período de guerra integral y a la fase de diálogo, según hemos visto al referirnos a la historia de la guerra y a la historia de la paz. Durante ella la política de negociación trascendió el empleo táctico de la misma para pasar a ser un componente de la estrategia. O sea, ha pasado a ser parte importante de la nueva estrategia de "desgaste" y de "guerra política" en que ambos bandos se involucran en esa época. Habrá, desde tal cualificación de dicha politica, determinadas coyunturas presididas por la negociación, por los hechos políticos generados desde ella, que logran catalizar la dinámica política.

Es importante en esta etapa la reformulación estratégica que realiza la alianza FDR-FMLN, la cual queda plasmada en su propuesta "de seis puntos", dada a conocer en julio de 1986. El planteamiento cede radicalidad respecto posturas anteriores, lo que es congruente con el nuevo carácter estratégico - ya no meramente táctico- que ha adquirido la política de negociación. Ahora, la propuesta no irá tanto dirigida hacia las propias bases, como hacia las fuerzas del bloque antagónico. Ya no se exige el desmantelamiento de la Fuerza Armada - "ambos bandos mantendrán sus ejércitos y sus armas"-; se enfatiza frente a la clase empresarial que "se respetará el derecho a la propiedad privada" y se propone un sistema de economía mixta; se plantea a las diversas fuerzas políticas la conformación de un gobierno transitorio donde los Frentes participarían "como uno más de sus componentes" y se postula por elecciones en las que éstos se comprometen a participar. A los Estados Unidos le piden que "saque las manos del conflicto" y que permita "una solución entre salvadoreños", en un planteamiento que ya no insiste en sentar a la gran potencia a la mesa de negociación como parte del conflicto.

Aunque esta propuesta insurgente sería en su momento, al igual que otras, desechada por la parte gubernamental, la concepción que la inspira se mantendrá en gran medida, de lo que se deduce que no debe minimizarse su importancia y su relativa eficacia en el efecto acumulativo que genera en el proceso global. Igualmente con la del año siguiente, la propuesta "de 18 puntos", centrada en el tema de la humanización y limitación del conflicto. Estratégicamente, el sentido de la misma era salirle al paso a la tendencia al escalamiento bélico y a la sofisticación armamentística que experi- 
mentaba la guerra, ante el creciente involucramiento estadounidense. Sin embargo, la coherencia argumentativa y la lógica humanitaria con que había sido formulada, volvía difícil a la contraparte reaccionar con un simple rechazo a los aspectos puntuales que eran ahí abordados. Ciertas medidas concretas - sobre la repatriación de los refugiados, el derecho al libre tránsito en las zonas conflictivas, el respeto hacia la población civil y a los activistas políticos, entre otros- serían acordadas y, al menos parcialmente, llevadas a la práctica por las partes beligerantes. De tal manera, una sutil red de compromisos mutuos había empezado a tenderse entre las dos partes enfrentadas, que ya no tenían del todo "las manos libres" en una situación de guerra que dejaba de entenderse como un estado del "se vale todo" y lentamente imponía reglas, normas de conducta y principios ético-políticos a los que sujetarse.

Cuando en enero de 1989 el FMLN hizo su novedoso planteamiento de respetar y participar indirectamente en las elecciones, a cambio de su posposición, entendemos que ello supuso el salto dialéctico que cerraba el período anterior, para dar paso a la tercera etapa. Detrás de esta propuesta prevalecía aún una estrategia para ganar la guerra, de la cual la política de negociación demostraba ser ya parte sustancial. También estaba imbuida por consideraciones de tipo táctico y coyuntural, dada la poca antelación con que fue dada a conocer la propuesta respecto al evento electoral. Por otro lado, las pocas posibilidades de victoria que las encuestas le daban a la democracia cristiana eran probablemente parte de la motivación que la inspiraba. La propuesta tal parecía un guiño cómplice hacia el partido de Napoleón Duarte - a la sazón Presidente- a fin de impedir un gane eleccionario al corto plazo de su rival ultraderechista y preparar las condiciones para algún pacto a futuro, en dirección a lo que después se propagandizaría con el lema "todos contra ARENA".

No obstante, lo importante de ella no estaría tanto en su origen y motivación, como en sus consecuencias. Ni la correlación de fuerzas del PDC con la derecha, ni su propio comprometimiento anticomunista y contrainsurgente, le permitieron a la democracia cristiana considerar con seriedad esta propuesta, la cual fue rápidamente rechazada por el gobierno de Duarte. Sin embargo, el planteamiento era realmente novedoso y estaba destinado a dejar una 
profunda huella en el proceso, aún a pesar de no haber sido en su momento aceptado ni discutido seriamente. En su "Propuesta para convertir las elecciones en una contribución a la paz", el Frente por primera vez lograba articular en una propuesta, elementos esenciales de su propia estrategia con otros de la estrategia enemiga. Básicamente, combinaba su concepción de negociación con el elemento elecciones. Es decir, al plantear fusionadamente lo que constituía el núcleo de la "política de la guerra contrainsurgente" con el de su propia "política de la guerra revolucionaria", prácticamente ambas tendían a quedar anuladas en esta función belicista anterior. La audaz formulación del FMLN desarticulaba la lógica de la postura enemiga, al tiempo que obligaba al propio Frente a un superior nivel de elaboración teórica. La negociación alcanzaba, desde este momento, la dimensión teórica al forzar una revisión de los planteamientos que habían prevalecido hasta entonces. La política de negociación había alcanzado el estadio de la teoría, participaba ahora de ella, desarrollándola y modificándola.

Efectivamente, tanto los propósitos que presidian el accionar de las partes, como las vías para el logro de los mismos, tenían que ser revisados, a la luz de las nuevas posibilidades que había abierto la oferta insurgente. Si la vía electoral se pensaba que podía consitituirse en una alternativa para acceder al poder, eso implicaba revisar el planteamiento teórico de "la toma del poder". El FMLN empezó entonces a discutir las "variantes de la victoria" y la posibilidad de un triunfo "por etapas". Incluso el problema del poder político en cuanto tal -si éste es algo único e indivisible o si puede "tomarse" por partes- era teóricamente analizado. También por la contraparte era estudiada la posible seriedad de la propuesta del Frente y sus implicaciones prácticas, en el caso de considerar aceptarla. Los riesgos para ambas partes eran evidentes pero, por ello mismo, también debían serlo las posibles ganancias. ¿Cuál de las dos estrategias podría predominar si la negociación y las elecciones dejaban de manejarse contrapuestas y se presentaban reunidas en el curso futuro de los acontecimientos? Por otra parte, ¿qué garantías cabía exigir a la contraparte para asegurarse de no caer en una simple estratagema del adversario?

A partir de la instalación de la mesa negociadora en abril de 1990 y en la medida que, coadyuvado por el papel mediador de 
las Naciones Unidas y la presión de la comunidad internacional, se dan avances en el proceso de negociación, éste empieza a desarrollar una incidencia sobre el tema de los métodos a utilizar y las metas a alcanzar. Es decir, la política de negociación se involucra en la dimensión doctrinaria del pensamiento global de las partes. Hay una tendencia a la revisión de la doctrina política que tiene su origen en la dialéctica interna que se ha venido generando en el proceso, pero que es asimismo poderosamente influida por los grandes cambios acaecidos en el mundo a partir de la caída del muro de Berlín. El FMLN es también fuertemente impactado por la derrota electoral de los sandinistas en 1990 la que, no solamente pone en dificultades logísticas a la conducción estratégica del exterior, sino que coloca también sobre el tapete decisivas preguntas de importancia teórica y doctrinaria.

Ha quedado evidenciado en Europa del Este y también en cierta forma en la Nicaragua sandinista, que no son equivalentes victoria y triunfo: una revolución triunfante puede resultar revertida, la victoria momentánea puede convertirse en antesala de la derrota de la revolución. La simple toma del poder no resuelve por sí misma los problemas históricos que enfrenta la revolución. Será preciso prestar más atención a la correlación global de fuerzas y a las condiciones específicas en que la revolución logra alzarse con la victoria. Lo cual significa la necesidad de abordar la cuestión de una reformulación profunda de la estrategia global, de la teoría y doctrina revolucionarias, para dar respuesta a la nueva exigencia de viabilidad, al mediano y largo plazo, de un proyecto histórico de transformaciones revolucionarias, en las condiciones de atraso y capitalismo dependiente de las sociedades del Tercer Mundo. En el FMLN empieza entonces a considerarse que la victoria total que ha resultado inalcanzable, quizás tampoco era deseable.

La relativa perplejidad teórica y doctrinaria en que queda sumida la conducción rebelde afecta asimismo a su contraparte. Esta tiene dificultades para entender las nuevas prioridades políticas que emergen en los Estados Unidos a raíz del hundimiento del "mundo socialista", a favor ahora de procesos de democratización, de desmilitarización y de solución política de los conflictos. Tampoco le resulta fácil valorar objetivamente las intenciones reales y los propósitos últimos del FMLN. Esta cuarta etapa se caracte- 
riza pues por grandes transformaciones en la concepción teórica y doctrinaria de las partes, que abarcan sus consideraciones sobre la naturaleza del poder, su ejercicio, la vía de acceso al mismo, la relación entre Estado y sociedad civil, etc. Mientras prosigue el forcejeo en la mesa de negociaciones en torno a cuestiones puntuales, se producen cambios en la doctrina de las partes y la inserción de la política de negociación como un nuevo componente doctrinario. En las pláticas entre jefes insurgentes y líderes empresariales se harán evidentes los mutuos vacíos de concepción y la readecuación doctrinaria que hay de ambos lados.

En esa evolución es evidente la nueva hegemonía de la doctrina neoliberal entre el sector dominante, la que se impone frente al grupo doctrinariamente aferrado al anticomunismo ultranacionalista. En la polémica entablada, que adopta carácter público en cuanto ésta se expresa en las páginas de los dos periódicos de mayor circuiación nacional, los "nuevos" valores (del "viejo" liberalismo) consiguen imponerse con sorprendente facilidad y lo hacen adoptando la pretensión de una "desideologización". Cobra primacia el ideal de un "Estado de Derecho" -lema que el Presidente de la República, Alfredo Cristiani, incluirá en su rúbrica del documento de Chapultepec-y pronto los ataques contra el "fanatismo", el "extremismo" y la "intolerancia" cobrarán rasgos de unanimidad en los medios de comunicación y en el lenguaje de los políticos. También en el FMLN los sesgos "dogmáticos" y autoritarios de su pensamiento serán ahora rechazados, en una evolución que tiende hacia el "realismo" y el "pragmatismo", según un todavia inconfeso pero ya bastante unánime viraje al reformismo gradualista.

La quinta etapa se entrelaza con la anterior, aunque tentativamente podríamos considerar septiembre de 1991, con los trascendentales acuerdos de Nueva York, como inicio de una inflexión. Debe recordarse que en esta decisiva reunión-desarrollada en la sede central de la ONU con la participación personal de su Secretario General, de los 5 miembros de la Comandancia General del FMLN y del Presidente de la República- las partes acordaron aspectos trascendentales de la solución negociada, como el desarme y la transformación en partido político del FMLN, el carácter permanente de la Fuerza Armada, su depuración y reducción, ade- 
más de establecer el tipo de composición y funciones de la nueva policía civil, PNC, de la Comisión ad hoc, así como de la COPAZ, etc. A partir de ese punto el pensamiento en torno a la negociación alcanza el nivel de la ideología, convirtiéndose en motor de importantes cambios en la esfera ideológica. Esta nueva dinámica se hará mucho más evidente a partir de la firma del Acuerdo de Paz en Chapultepec, el 16 de enero de 1992, y a lo largo de la fase de cumplimiento de los diversos compromisos.

En este período, sin una profunda renovación ideológica, que afectaría a los valores y a la propia concepción de mundo, difícilmente los dirigentes de uno y otro bando hubieran conseguido de sus bases, cuadros, jefes y mandos intermedios, el considerable grado de aceptación - sin escisiones ni insubordinaciones relevantes- a la ejecución de los compromisos contraídos. La elaboración ideológica - no sólo teórica y doctrinaria- es evidente en la común exaltación de nuevos valores como la estabilidad, la tolerancia, el respeto mutuo y el consenso, entre otros. Va extendiéndose un discurso, que se vuelve prácticamente unánime en el espectro político, centrado en la paz, la democracia, la concertación, la gobernabilidad, la convivencia social y el desarrollo sostenible. Se refleja en él una nueva "concepción de mundo", una diferente conceptualización del mundo político. Que tal discurso es de naturaleza ideológica es algo indiscutible, cosa que lejos de resultar refutada más bien se corrobora por el hecho de que, en los "nuevos tiempos" que vivimos, su contenido nos parezca totalmente razonable y su necesidad, de todo punto "evidente". Este novedoso discurso viene a encubrir ideológicamente la existencia de las contradicciones sociales, la persistencia de una no resuelta crisis estructural la misma que estuvo en el origen de la guerra- y la cuestionable viabilidad de un proyecto, casi idílico, de Nación.

\section{Dialéctica entre concepción programática y política de negocia- ción}

omo resultado del proceso de transformaciones ideológicas y de cambios en el pensamiento estratégico global de las partes, se da un marcado contraste entre sus planteamientos al origen del conflicto y los que formularán al llegar a su finalización. Al avanzarse hacia la solución negociada, la política de negociación moti- 
vaba en los actores políticos readecuaciones programáticas y revisiones en su posición teórica y doctrinaria, cuyo examen nos ayudará a entender mejor el camino recorrido y las coordenadas en que hoy aparece inscrito el escenario de la transición.

Un seguimiento al detalle de este movimiento dialéctico en los diferentes actores que componen los dos bandos excede las dimensiones y posibilidades de esta investigación. Se da el caso que, por ejemplo, del lado del régimen podemos contabilizar nada menos que once formaciones partidarias de derecha y centro-derecha funcionando en la década pasada, de las que siete se mantenían participando en las elecciones de 1989. Si se quisiera ser acucioso, además de los distintos documentos programáticos de cada partido, convendría también tomar en cuenta los planteamientos de instituciones que, como FUSADES y las gremiales del sector privado, incidieron poderosamente en el pensamiento político dominante y en las políticas específicas impulsadas desde el gobierno. Sin embargo, no nos parece imprescindible, para los propósitos de nuestro estudio, una revisión tan pormenorizada. Incluso podriamos correr el riesgo de que "los árboles no nos dejaran ver el bosque"; es decir, que al querer examinar en detalle a cada partido, perdiéramos la visión general de un sistema político que reaccionaba de conjunto, frente las cambiantes políticas de la revolución que enfrentaba.

El bando insurgente es el que desde un inicio, como ya hemos visto, se identificó con la política de negociación y el que generó mayor número de propuestas y planteamientos, manteniendo siempre la iniciativa en este terreno. La evolución de su pensamiento condicionaría y "arrastraría" a la contraparte a una transformación correspondiente. El hecho es que los dos extremos ideológicos se encontrarán, en la conclusión negociada de la guerra, en un cercano lugar concepcional adonde "desembocan" finalmente. Aunque el análisis del pensamiento estratégico de la izquierda salvadoreña, que sigue hoy en plena evolución, por ahora sólo puede tener carácter tentativo y provisional, no obstante, un examen preliminar puede resultarnos ilustrativo y esclarecedor.

Hemos analizado un total de doce documentos elaborados y difundidos entre los años 1980 a 1990 por la alianza FDR-FMLN o por uno solo de los Frentes en solitario. Tres de ellos constituyen 
plataformas programáticas en las que se definen principios, metas y objetivos. Son ellas, la del FDR en 1980 del Gobierno Democrático Revolucionario, GDR, la de 1984 del GAP, Gobierno Provisional de Amplia Participación, y el planteamierto contenido en la "Proclama a la Nación" del FMLN de 1990, que reúne su última concepción sobre la revolución democrática. Hay además un total de diez propuestas operativas respecto al proceso de diálogo-negociación, en las que se abordan algunas de las cuestiones sustanciales a negociar y principalmente aspectos de procedimiento. Un caso especial es el documento de enero de 1984, en el que, a continuación de la plataforma programática del GAP, se incluyó un apartado dedicado a cómo operativizar la respectiva negociación, motivo por el cual lo hemos contabilizado doblemente, como programa de gobierno y como propuesta de negociación.

A efectos de análisis hemos examinado diferenciadamente en las distintas propuestas lo que es sustantivo de lo que se refiere a procedimiento. Nos hicimos la pregunta sobre qué tanto se aleja la última formulación de la insurgencia, del tipo de transformaciones a que aspiraban los Frentes con anterioridad. A fin de realizar un estudio comparativo identificamos 16 variables relativas a aspectos de contenido y 8 referidas a cuestiones de procedimiento. Decidimos la conveniencia de agrupar dichos 16 componentes sustanciales de acuerdo a su primera conceptualización, según la cual la revolución en El Salvador era, por su carácter: democrática, antioligárquica y antiimperialista. De tal modo, el seguimiento que hemos hecho de las distintas variables en los sucesivos planteamientos insurgentes nos refleja, bastante fielmente, los cambios cualitativos en su pensamiento estratégico, con respecto esas tres connotaciones esenciales de su estrategia global.

El balance muestra, a grandes rasgos, que el Frente mantuvo hasta el final lo básico de su concepto de revolución democrática. Puede decirse, además, que tuvo bastante éxito en este nivel. Llama la atención, por ejemplo, el fuerte paralelismo que hay entre la agenda de la negociación y la lista de componentes que se deducen de sus planteamientos programáticos anteriores. Hemos identificado las siguientes variables: 1) consideraciones respecto a la Fuerza Armada y el poder militar, 2) respecto a los cuerpos de seguridad, 3) todo lo relativo a derechos humanos y fin de la impu- 
nidad, 4) el sistema judicial y la Corte Suprema de Justicia, 5) el gobierno o poder formal, 6) el sistema electoral, 7) el sistema politico y su actitud frente a los demás partidos y 8) el régimen constitucional y su posición hacia la Constitución vigente. Se dan, desde luego, diferencias en los énfasis y un cierto rebajamiento general de planteamientos. Pero en muchos puntos eso no se dará sino en la negociación propiamente dicha, cuando resulta lógica la necesidad de hacer concesiones y donde hay además cierta confluencia con el planteamiento asimismo democratizador de la contraparte.

Distinto es el caso de la revolución anti-oligárquica. Aquí la devaluación de los planteamientos es sensible en las 4 variables que hemos identificado: 1) reformas estructurales, 2) régimen de propiedad, 3) movimiento laboral y cooperativo y 4) posición sobre el "libre" mercado y el papel del Estado en la economía. Respecto las reformas, después del vago planteamiento por su realización "plena" -que ya comentamos anteriormente-, a partir de la victoria electoral de ARENA en 1989, el Frente pasó a exigir que se mantuviera la nacionalización de la banca y del comercio exterior. En la negociación, no obstante, el FMLN aceptaría como un hecho consumado la privatización efectuada en ambos casos por el gobierno arenero.

Con respecto a la reforma agraria, en la Proclama de 1990 todavía se pedía su profundización, con un confuso criterio de que ésta fuese "verdaderamente campesina". El tema quedaria después fuera de la agenda del FMLN, argumentándose que el programa de transferencia de tierras - a los ex-combatientes de ambos bandos-constituía en sí "una segunda reforma agraria". Eso era una simple falacia: ni por el número de beneficiarios, la cantidad de tierras afectadas, o los criterios de implementación (el dueño decide si quiere o no vender, así como el pago, según precios de mercado), son de ninguna forma comparables. La realidad de los hechos es que los supuestos "beneficiarios" están ahora en manos de los bancos, a los que, con lo que logren de sus cosechas, deben cancelar año con año sus créditos por el pago de la parcela, los préstamos para cultivarla, más el crédito para construcción de la vivienda. Todos los expertos que hemos consultado opinan unánimemente que es sólo cuestión de tiempo para que la mayoría de dichas tierras regrese a las manos de sus antiguos propietarios. 
La "reforma urbana" que se incluia en las demandas del Frente resultará al final simplemente añadida como un componente más de la plataforma electoral de la Coalición en 1994. Por otro lado, en su programa de revolución democrática, el FMLN hacía referencia a la creación de un "polo económico popular", el cual debería llegar a perfilarse como "factor determinante" en la marcha de la economía nacional. Lo ilusorio del planteamiento estriba en que no se hace acompañar de una correspondiente política de protección y estímulo estatal, sino que se espera de las "nuevas" empresas, las cooperativas y comunidades, que entren a competir exitosamente con el sector privado, en un mercado altamente monopolizado. Mientras en 1980 se postulaba por un Estado activo en la economía, que regulase precios, salarios y servicios sociales, o se abogaba en 1984 por un plan gubernamental de empleo masivo, al fin la izquierda salvadoreña ha terminando aceptando bases doctrinarias de su contraparte. Se acepta en la postguerra que la economía se "autoregule" según las leyes del libre mercado, que se liberen las fuerzas económicas en la competencia capitalista, que se reduzca el papel del Estado y se entre a un proceso de racionalización y modernización del sistema. En la coincidencia doctrinaria con principios del neoliberalismo la izquierda refleja su claudicación ideológica, dándole bajo perfil a los que fueron componentes de una concepción anti-oligárquica.

Si en el carácter anti-oligárquico de las transformaciones se ha dado un sensible rebajamiento de planteamientos, que desvirtúa prácticamente esa dimensión, en la revolución anti-imperialista el abandono es total, siendo el resultado obtenido tras la solución negociada casi inverso a lo antes postulado por la insurgencia. Veámoslo a través de las 4 variables que en las sucesivas propuestas identificamos: 1) posición hacia la situación de dependencia y la soberanía nacional, 2) sobre la intervención de Estados Unidos y presencia de personal e intereses norteamericanos, 3) principios de política exterior y 4) actitud frente a gobiernos amigos, las Naciones Unidas y la comunidad internacional.

En la medida que la Administración estadounidense cambió su política guerrerista y dio su apoyo al proceso de negociación, el FMLN silenció - lógicamente- sus críticas pasadas. Pero no se limitó a esto: en la práctica olvidó su caracterización del imperio, 
como dando a entender que éste había cambiado su carácter, o que nunca hubiera sido tal. Buscó ahora su amistad y apoyo, convirtiéndose de hecho en un vehículo político inesperado para la continuidad de la intervención norteamericana en la economía, la política y los asuntos salvadoreños. El recurso al asesoramiento por una empresa especializada norteamericana para confeccionar su "imagen" durante la pasada campaña electoral o el mismo lema escogido - traducción exacta del slogan "People first" utilizado por el actual Presidente de los Estados Unidos, Bill Clinton- son sólo dos pequeñas muestras del vuelco ideológico y concepcional de la izquierda salvadoreña, que antes ostentaba orgullosamente en el continente latinoamericano el calificativo de fuerza anti-imperialista.

De ahí la ambivalencia con que debe ser juzgada la profunda transformación de los actores en este proceso, potenciadora de la solución negociada, pero también factor de debilidad de la misma. No es de extrañar, por ello, que de los cuatro propósitos con que se definió en la agenda el sentido del proceso de negociación, sólo uno de ellos, el de la solución política al conflicto, haya sido plenamente alcanzado. No se ha logrado con tal plenitud ni la real democracia, ni el respeto a los derechos humanos, ni la reunificación y reconciliación de la sociedad salvadoreña. Las partes han demostrado estar más preocupadas por asegurar las garantías mutuas y la irreversibilidad del proceso de paz, que por el contenido de las transformaciones puntuales. En la misma negociación se dio ese corrimiento en las prioridades, tendiendo a ser aspectos relativos al procedimiento los que centraron la atención. Lo vimos en ciertos momentos puntuales, como en abril del 91, en el debate sobre las reformas a la Constitución, cuando éste se centró mayormente en el artículo 248 que define el procedimiento para la reforma constitucional. En septiembre sería el punto de si Cristiani debía o no hablar con el FMLN y así sucesivamente. En la fase de cumplimiento de los acuerdos aún más acusadamente serian consideradas prioritarias, por encima del contenido mismo, cuestiones de ese tipo: el calendario, la simultaneidad, la reciprocidad, las garantías, la verificación o el financiamiento.

Puede decirse que el tipo de solución al conflicto condicionó asimismo el contenido de la misma, que el método de la negociación 
influyó poderosamente en la sustancia de lo acordado en la fórmula de paz alcanzada. Cabría decir que en la relación dialéctica entre los aspectos sustantivos objeto de negociación y las cuestiones de procedimiento de la misma, tenderían a imponerse éstas últimas como las más decisivas. Ellas doblegarán bajo su lógica incluso los puntos de contenido más esenciales y a los que las partes estaban más aferrados. Reflejo de ello será asimismo el que la solución negociada privilegie claramente aquéllo que tiene que ver con los efectos de la guerra, más que lo que está ligado a las causas de la misma. Esto no necesariamente tenía que ser así, mas es justificado con el discurso de garantizar un no regreso a la guerra. Desde el momento en que la voluntad de las partes se decidió firmemente por la vía negociada para alcanzar una salida política a la guerra, la cuestión de las garantías tomaba para ellas una importancia definitiva, aceptando con mayor facilidad el sacrificar determinadas cuestiones de contenido con tal de que queden aquéllas suficientemente aseguradas. Estas consideraciones nos introducen al tema de la dialéctica entre el fin y los medios, que pasamos a desarrollar a continuación y con la que concluiremos ese dibujo preliminar de una posible "historia de la democracia" en El Salvador.

\section{Dialéctica entre los fines y los medios}

T a misma tendencia en la relación entre el procedimiento y la ta a la prioridad dada ahora a las nuevas formas de hacer política por encima de los contenidos concretos y diferenciadores de la política de unos y otros. Se repite fácticamente la clásica observación de Hegel de que en la historia los medios terminan imponiéndose sobre los fines. Es un recorrido dialéctico que ya hemos descrito antes al referirnos a la relación entre dinámica militar y política, o a la establecida entre política de negociación y de democratización. Entre los fines y los medios la relación atravesará por 5 momentos sucesivos: la exclusión absoluta, la necesidad mutua, la paradoja de lo equiparable no equivalente, el dilema entre los idénticos no iguales y, por último, la identificación o identidad final. Desde el momento primero en que el medio negociador es excluido por el fin político que se persigue, pasando por los momentos 
intermedios de entrelazamiento y acercamiento entre medios y fines, se llega al momento dialéctico culminante de la correspondencia entre los fines perseguidos y los medios empleados.

En esa identidad última lo que ha resultado transformado son los fines. Es el precio que se ha pagado en el logro de los mismos, por lo que desde el punto de vista de los cambios revolucionarios, del fin revolucionario, éste aparece francamente devaluado. En la plataforma de revolución democrática de 1990 el FMLN resumía en cuatro rubros la esencia de su planteamiento: democratización, desmilitarización, nuevo orden económico-social y política exterior independiente y soberana. Terminaba esta Proclama a la $\mathrm{Na}$ ción con un compromiso enfático: "No renunciaremos jamás a estos propósitos!". Lamentablemente, sólo el primero de ellos ha sido parcialmente cumplido, y el "jamás" tan enérgicamente pronunciado duraría escasamente dos años. En diciembre de 1992 la cúpula del Frente negociaba en secreto con el gobierno un no previsto programa especial para 600 de sus jefes militares y cuadros políticos, que incluye becas para estudios superiores y créditos para vivienda y para actividades empresariales. El título inicial de la propuesta, convenientemente sustituido en la versión final del documento, era en sí mismo sugestivo y revelador: "De comandantes guerrilleros a empresarios". El programa fue aprobado rápidamente y cuenta con fondos suficientes, principalmente de AID; los beneficiarios cursan estudios de administración de empresas en instituciones privadas, incluida FUSADES, y muchos ya han fundado sus propias empresas con los créditos recibidos. Mientras, la mayoría de ex-combatientes del FMLN, los lisiados de guerтa y los familiares de los asesinados y desaparecidos durante el conflicto, todavía pugnan por obtener los fondos para sus programas de reinserción o compensación. En tal circunstancia, ¿puede extrañar que haya surgido la crisis interna en el seno de la izquierda salvadoreña?, ¿puede extrañar que haya un creciente distanciamiento y desconfianza entre bases y cúpulas, entre militantes y dirigentes, entre las masas y los partidos?

En nuestro tiempo de transición resulta que todo el mundo se considera democrático y quiere ser reconocido como tal, pero el problema es que hay muy variadas formas de entender la democracia. Mientras para unos la democracia es un puente, que debe 
llevarnos a alguna parte, para otros es más bien un puerto de llegada. ¿Cómo considerar nuestro presente de paz y democracia? ¿Es solamente un peldaño más, aunque importante, en la escalera de la historia o constituye su grada última, algo así como el fin de la historia? Detrás de esas preguntas está el problema de la relación entre paz, guerra, democracia y revolución. Quien esgrime la falsa lógica de que, puesto que estuvo en la guerrilla haciendo la guerra, ello "demuestra" que ha sido revolucionario, el paso lógico siguiente es aducir que, dado que al final se hizo la paz, ya no será posible seguir siendo revolucionario. El actual pacifismo tiene entonces una base falsa, como simple prolongación ideológica del anterior militarismo. Desde esta visión no es sorprendente que la tendencia más militarista del FMLN se presente hoy como la más radicalmente volcada al reformismo conformista, que tanto tiene de claudicación ideológica.

No es de extrañar, por tanto, que en la postgueira haya un acercamiento y signos de un flirteo político entre los que podemos llamar "la izquierda de la derecha" y "la derecha de la izquierda". El centro como espacio sin identidad ni definición propias-que se define en función de la definición de otros, sin los cuales el centro no es centro- aparece como el lugar ideal para la indefinición y falta de identidad, a que se dejan arrastrar los actores más proclives al llamado de la coyuntura. La ideología desideologizada y la política despolitizada pareciera emerger como inconfeso ideal de postguerra. ¿Puede en tal situación hablarse de una "revolución negociada"? ¿No será éste un despropósito teóri$\mathrm{co}$, útil solamente para el consumo periodístico? Conseguido el cambio mediante un medio que básicamente es la reforma dificilmente podia esperarse que el fin mantuviera su anterior carácter revolucionario. Incluso la izquierda que sigue llamándose y considerándose izquierda, dudosamente puede seguir siendo caracterizada como izquierda revolucionaria.

Una postguerra marcada por la persistencia y exacerbamiento de la violencia, en parte política, pero sobre todo delincuencial, es imposible que sea vivida socialmente como un tiempo de paz. En una transición "a la democracia" en la que persiste una situación de pobreza generalizada que afecta a dos terceras partes de los salvadoreños, de los que la mitad están sumidos en la extrema 
pobreza, no es fácil que la democracia alcance credibilidad social o que sea aceptada en sí misma como un valor absoluto. De ahí la actualidad y necesidad de la pregunta por la revolución, por cambios de índole revolucionario, que consoliden la paz y complementen la democracia. Lejos de ser antagónicas, la democracia y la revolución se apoyan y necesitan mutuamente, asi como ocurre entre la paz y la democracia. El reaccionario sofisma de que si se está por la paz y por la democracia no se puede al mismo tiempo estar por la revolución, no es por ahora contestado con la suficiente contundencia desde los actores políticos; sólo lo es desde la Academia, desde la Iglesia y desde ciertos núcleos organizados de las mayorías populares. En consecuencia, quienes antes depositaron su $f e$ en actores políticos abanderados del cambio social, ahora ponen su esperanza en los propios sujetos sociales, potenciales protagonistas de su propia liberación.

Por ahora nos hemos dado a la tarea de escribir esta triple historia de la guerra, de la paz y de la democracia, no tanto desde el final del camino, como en plena travesía. Dejamos pendiente una "historia de la revolución", que aún está por escribirse en El Salvador, donde apenas se dio inicio a su prólogo. Los "viejos" partidos están ahora todos en crisis. Bienvenida sea. Hoy por hoy, se debe abrir paso lo nuevo, con menos autoritarismo y más autenticidad, con más humildad y menos vanguardismo. Lo nuevo se verá emerger desde las mayorias sufrientes, que reclaman su hora y su momento, para alcanzar su redención. Demasiado prematuro nuestro presente para poder nombrar el futuro, no lo es para asegurar que éste, en la forma de un tiempo de maduración, con plena seguridad legará. No importa lo minoritaria que hoy sea la convicción al respecto. Sólo quienes, además de haber perdido la confianza en los dirigentes, la han perdido también en el pueblo, tienen motivo para la desesperanza. Mantengámonos, pues, esperanzados, en que se podrá realizar colectivamente la esperanza. Que así sea.

14 de septiembre de 1994. 


\section{Bibliografía del marco teórico}

Althusser, L.: Sobre la relación de Marx con Hegel; en Hyppolite e.a.: "Hegel y el pensamiento moderno", Ed. Siglo XXI, México, 1973.

"La revolución teórica de Marx"; Ed. Siglo XXI, Madrid, 1967

Aron,.R.: "Paz y guerra entre las naciones"; Ed. Revista de Occidente, Madrid, 1963.

Bloch, E.: "Sujeto, objeto. El Pensamiento de Hegel"; F.C.E., México, 1982.

Bobbio, N.: "El futuro de la democracia"; Ed. Plaza y Janés; Barcelona, 1985.

Bourgeois, B.: "El pensamiento político de Hegel"; Amorrortu Ed., Buenos Aires, 1969.

Bouthoul, G.: “Ganar la paz"; Ed. Plaza y Janés; Barcelona, 1970.

Brodie, B.: "Guerra y política"; F.C.E., México, 1978.

Capella, J.R.: Los límites de la democratización capitalista; Rev. "Mientras tanto" \#40, primavera 1990, Barcelona.

Castañeda, J.: "La utopía desarmada"; Ed. Planeta, México, 1993.

Clausewitz,C.: "De la guerra"; Ed. Labor, Barcelona, 1976.

d'Hondt, J.: "Hegel, filósofo de la historia viviente"; Amorrortu Ed., Buenos Aires, 1971.

"De Hegel a Marx"; Amorrortu E., Buenos Aires, 1974

Duc-thao, T.: "El materialismo de Hegel"; Ed. Siglo XXI, Buenos Aires, 1965.

Duverger, M.: "Introducción a la política"; Ed. Ariel, Barcelona, 1970.

Ellacuría, I.: "Filosofía de la realidad histórica"; UCA Ed., San Salvador, 1990.

Gadamer, H.G.: "La dialéctica de Hegel"; Ed. Cátedra, Madrid, 1988

Hegel, G.W.F.: "Lecciones de Filosofía de la Historia"; Alianza Ed., Madrid, 1980. "Fenomenología del Espíritu"; F.C.E., México, 1966.

Hyppolite, J.: "Introducción a la filosofía de la historia de Hegel"; Ed. Calden, Buenos Aires, 1970.

Lechner, N.: "Los patios interiores de la democracia"; F.C.E., Santiago de Chile, 1990.

Lukács, G.: "El joven Hegel y los problemas de la sociedad capitalista"; Ed. Grijalbo, México, 1963.

Marcuse, H.: "Razón y revolución. Hegel y el surgimiento de la teoría social"; Alianza Ed., Madrid, 1971.

Marx, K.: "El 18 Brumario de Luis Bonaparte"; Ed. Progreso, Moscú, 1982.

Tierno G., E.: "Antología de Marx"; Ed. Cuadernos para el Diálogo, Madrid, 1972.

VV.AA.: "Las ideologías y sus aplicaciones en el siglo $X X^{\prime \prime}$; Instituto de Estudios Políticos, Madrid, 1962

Wahl, J.: "La lógica de Hegel como fenomenología"; Ed. La Pléyade, Buenos Aires, 1973.

Weber/Campora: 'Los espejos rotos. Reflexión conjunta sobre la actual crisis civilizatoria", Ed, Trilce, Montevideo, 1992. 


\section{Bibliografía histórica}

Barba, J.: Probabilidad de la democracia en El Saloador ; en Barba e.a.: "La democracia hoy"; Istmo Ed., San Salvador, 1994.

Benitez, R.: "La teoría militar y la guerra civil en El Salvador"; UCA Ed., San Salvador, 1989.

Córdova, R.: El Salvador: las negocinciones de paz y los retos de la postguerre; mimeo, San Salvador, 1992.

Procesos electorales y sistema de partidos en El Saloador (1982-1989); FUNDAUNGO; San Salvador, 1992

Ellacuría, I.: "Veinte años de historia en El Salvador (1969-1989) Escritos políticos"; UCA Ed., San Salvador, 1991.

Gómez, 1.: El proceso electoral de 1994; Avances de Investigación \#3, FLACSO, San Salvador, 1994.

Harto, F.: “Los procesos de negociaciones de paz en América Central (1979-1991)"; tesis doctoral, Universidad Complutense, Madrid, 1991.

LaFeber, W.: “Revoluciones inevitables"; UCA Ed., San Salvador, 1989.

Guidos B., R.: El tiempo del adiós. La izquierda y el cambio social en El Saloador; Polémica \#16, enero-abril 1992, FLACSO, San Salvador.

Handal, S.: "El socialismo: ¿una alternativa para América Latina?"; Publ. Alternativa, San Salvador, 1991.

Lungo, M.: "El Salvador en los 80: contrainsurgencia y revolución"; EDUCA, San José, 1990.

- Los obstáculos a la democratización en El Salvador; en Barba e.a., opus cit.

Medina, I.: "El Salvador: entre la guerra y la esperanza"; Universidad de Guadalajara, México, 1990.

Montalvo, A.: "Los acuerdos de paz un año después"; CINAS, San Salvador, 1993.

Ribera, R.: El "signo de los tiempos" en el deoenir del tiempo histórico. El Salvador de 1960 a 1994: crisis, guerra, transición; REALIDAD \#38, marzo-abril 1994 UCA Ed., San Salvador.

Rousseau y los fundamentos de la democracia en El Saloador; Realidad económico-social \#35, sept.-oct. 1993, UCA Ed., San Salvador.

Transición democrática y proceso electoral; ECA \#543/544, enero-febrero 1994, UCA, San Salvador.

Democracia de baja intensidad: derecha fraudulenta, izquierda defraudante ; ECA \#545/546, marzo-abril 1994, UCA, San Salvador.

Rosa, H.: "AID y las transformaciones globales en El Salvador"; CRIES, Managua, 1993.

Samour, H.: Marco teórico-politico para la construcción de un orden democrático en El Salvador; ECA \#543-544, enero-febrero 1994.

Sobrino, J.: "Se puede vioir de otra manera". Analisis utópico-profético del proceso saloadoreño; ECA \#541/542, nov./dic. 1993, UCA Ed., San Salvador.

Tinoco, H.: "Conflicto y paz. El proceso negociador centroamericano"; Ed. Mestiza, México, 1989.

Torres R., E.: "El tamaño de nuestra democracia"; Istmo Ed., San Salvador, 1992.

Villalobos, J.: "Una revolución en la izquierda para una revolución democrática";

Ed. Arcolris, San Salvador, 1992. 
VV.AA.: El Informe de la Comisión de la Verdad: analisis, reflexiones, comentarios; ECA \#534/535; abril-mayo 1993, UCA, San Salvador Las elecciones de 1994; ECA \#545/546, marzo/abril 1994, UCA, San Salvador. A dos eños de le firme de los acuetdos de paz; Cuadernos de Trabajo \#5, FLACSO, San Salvador, 1994

Proceso electoral y democratización; Cuadernos de Trabajo \#6, FLACSO, San Salvador, 1994.

"Los escuadrones de la muerte en El Salvador"; Ed. Jaraguá; San Salvador, 1994.

Ejecución del Plen de Reconstrucción Nacional. Balance 93; Fundación 16 de enero, San Salvador, 1994

Balance del proceso de inserción; Fundación 16 de enero, San Salvador, 1994. 